\title{
Las instituciones de la democracia directa a nivel nacional en América Latina. Balance comparado: 1978-2010
}

Dr. Daniel Zovatto*

\begin{abstract}
Resumen
La transición a la democracia en América Latina muestra a lo largo de los últimos treinta años dos etapas principales. Una, durante los años 80 , década perdida en lo económico pero de gran avance en materia democrática. La otra, a lo largo de los años 90, caracterizada por la crisis de representación del sistema partidario y el descontento creciente con la política, situaciones que trataron de ser superadas en numerosos países de la región mediante una doble vía: reformas constitucionales por un lado, e incorporación de mecanismos de democracia directa por el otro. Así, en tiempos como los actuales, en que los parlamentos y los partidos no gozan de confianza ante la opinión pública, los mecanismos de participación ciudadana son vistos por ciertos sectores como una opción válida para mejorar la representación, incrementar la participación y mantener la estabilidad de los sistemas políticos. Se ha instalado así, en la agenda política latinoamericana, un debate en torno a los potenciales beneficios y riesgos de estas instituciones.
\end{abstract}

Determinar hasta qué punto estas instituciones de democracia directa han llegado para quedarse y cuáles han sido sus efectos principales en relación con los problemas respecto de los cuales tratan de dar respuesta, son los objetivos centrales de este trabajo, el cual abordamos en clave comparada, cubriendo en nuestro análisis desde la perspectiva geográfica, a los 18 países de América Latina y, desde la temporal, el periodo que va desde 1978 (fecha de arranque de la Tercera Ola en nuestra región) hasta marzo de 2010.

Palabras clave: Democracia representativa - democracia participativa - democracia directa - referéndum - consulta popular - participación electoral - iniciativa legislativa - revocatoria de mandato.

\begin{abstract}
The transition toward democracy in Latin America over the last twenty nine years can be broken down into two major periods: the first one covering the 1980s, considered a lost decade economically but rather progressive democratically; and the second taking in the 1990s, characterized by the representational crisis of the political party system and a growing discontent with politics. A twofold approach was used to deal with both of these latter situations in several countries throughout the region by making constitutional reforms and adopting direct democracy mechanisms. Thus, now when parliaments and political parties are the object of public opinion mistrust, some sectors view civic participation mechanisms as a valid option for enhancing representation, boosting participation, and keeping political parties stable. Hence, debate over the potential benefits and risks of these institutions has become established on the Latin American political agenda.

The main objectives of this document, which we are approaching from a comparative perspective, are to determine to what extent these direct democracy institutions are here to stay and what their most important impact has been on the problems being addressed. Our analysis covers the eighteen Latin American countries from the onset of the region's Third Wave of Democratization in 1978 to March 2010.
\end{abstract}

Keywords: Representative democracy - participatory democracy - direct democracy - referendum - popular consultation - electoral participation - legislative initiative - mandate recall.

* Director Regional para América Latina del Instituto para la Democracia y la Asistencia Electoral (IDEA Internacional). 


\section{INTRODUCCIÓN Y PRECISIÓN CONCEPTUAL}

La transición a la democracia en América Latina ${ }^{1}$ muestra dos etapas principales a lo largo de los 32 años que van desde 1978 a la fecha. Una, durante los 80, década perdida en lo económico pero de gran avance en materia democrática. La otra, en los 90, caracterizada por la crisis de representación del sistema partidario y el descontento creciente con la política, situaciones que generaron cambios en numerosos países de la región a través de una doble vía: reformas constitucionales por un lado e incorporación de mecanismos de democracia directa por el otro, como una manera de complementar o incluso, en algunos países, con el propósito de querer suplantar la democracia representativa.

Determinar hasta qué punto estas instituciones de democracia directa han llegado para quedarse, cuáles son sus principales modalidades y características, así como cuáles han sido sus efectos en relación con los problemas a los que intentan responder son los objetivos centrales de este trabajo, que abordamos en clave comparada cubriendo en nuestro análisis desde una perspectiva geográfica a los 18 países de América Latina y, desde una temporal, el periodo que va desde 1978 (fecha de arranque de la Tercera Ola Democrática en nuestra región) hasta hoy. Deseamos precisar que nuestro análisis se base fundamentalmente al ámbito nacional, dejando por fuera la aplicación de estos mecanismos en el nivel local, excepto cuando son tratados por la Constitución Política.

Antes de adentrarnos al estudio de nuestra materia, cabe indicar que por "instituciones de democracia directa" entendemos, en este trabajo, las diversas formas de participación política que se realizan a través del ejercicio del voto directo y universal. Su objetivo principal es involucrar al conjunto de la ciudadanía en el proceso de toma de decisiones sobre cuestiones públicas (actos o normas), y no el de elegir a los miembros de los poderes Legislativo o Ejecutivo (Aragón y López, 2000: 981).

\section{IMPORTANCIA DEL TEMA Y ESTADO DEL DEBATE}

¿Puede ser deseable lo poco posible? Una primera reacción sería decir que esta pregunta resulta irrelevante, ya que si la democracia directa es poco posible, entonces no tiene sentido preguntarse si es deseable. La historia indica que la experiencia de la democracia griega, más precisamente la ateniense, así como la de algunas de las comunas urbanas medievales, fue corta y que los grados de democracia "pura" que alcanzaron son bastante discutibles.

Las experiencias de Liechtenstein, de Italia, de algunos estados de la Unión Americana, pero sobre todo de Suiza (el ejemplo más citado y estudiado), evidencian la importancia que desempeñan las prácticas de democracia directa en el proceso de formación de la voluntad política. Sin embargo, si bien interesantes desde el punto de vista comparado,

\footnotetext{
1 El concepto de transición no se aplica para Costa Rica, Colombia y Venezuela, porque estos tres países ya
} tenían sistemas democráticos establecidos al inicio de la Tercera Ola en 1978. 
estas experiencias no permiten entender a cabalidad el funcionamiento de los mecanismos de democracia directa en nuestra región.

Más allá de estas consideraciones, lo cierto es que, en tiempos como los actuales, en que los parlamentos y los partidos gozan de una confianza muy baja ante la opinión pública², los mecanismos de participación ciudadana son vistos por ciertos sectores como una opción válida para mejorar la representación, incrementar la participación y mantener la estabilidad de los sistemas políticos. Así, se ha instalado en la agenda política latinoamericana un debate en torno a los potenciales beneficios y riesgos de estas instituciones.

Para un sector existe una contraposición peligrosa entre la democracia representativa y la directa, así como el riesgo de un posible uso demagógico de estas instituciones. Para otro, en cambio, esta supuesta contradicción es cosa del pasado, ya que como la experiencia comparada lo demostraría, las instituciones de democracia directa, más que una alternativa per se, deben verse como complemento de la democracia representativa.

\section{PRINCIPALES MODALIDADES EN AMÉRICA LATINA}

A nivel comparado, en América Latina hay una variedad de instituciones de democracia directa y una pluralidad conceptual y terminológica que podría generar confusión. Dado que la mayoría de las constituciones latinoamericanas denominan estos mecanismos con términos diferentes -iniciativa legislativa popular, plebiscito, referendo, consulta popular, revocatoria de mandato, cabildo abierto, para citar tan sólo algunas de las expresiones más usuales-, la búsqueda de una unidad de acepciones y conceptos que trasciendan el ámbito nacional resulta, aunque difícil, imprescindible para entender mejor cuando hablamos de este tema.

En nuestro caso, hemos clasificado los mecanismos de democracia directa en tres grupos: 1) consulta popular (plebiscito/referendo), por mucho el mecanismo más usado; 2) iniciativa legislativa popular, y 3) revocatoria de mandato. Conscientes de que toda clasificación presupone grados diversos de subjetividad y arbitrariedad, el propósito que nos anima es presentar un asunto complejo de la manera más clara posible.

De esta forma, un criterio de clasificación basado en el ámbito de aplicación distingue entre mecanismos de democracia directa de tipo personal (referidos a una persona o autoridad) o sustantivos (referidos a un tema). Asimismo, existen mecanismos catalogados por el origen de la iniciativa, es decir, "desde abajo" o popular, o "desde arriba" o institucional. Al respecto, en la siguiente gráfica se puede observar la diversidad de mecanismos.

2 De acuerdo con Latinobarómetro 2009, entre los latinoamericanos el Congreso tiene 34\% de confianza y los partidos políticos $24 \%$. 


\section{FIGURA 1}

Mecanismos de democracia directa

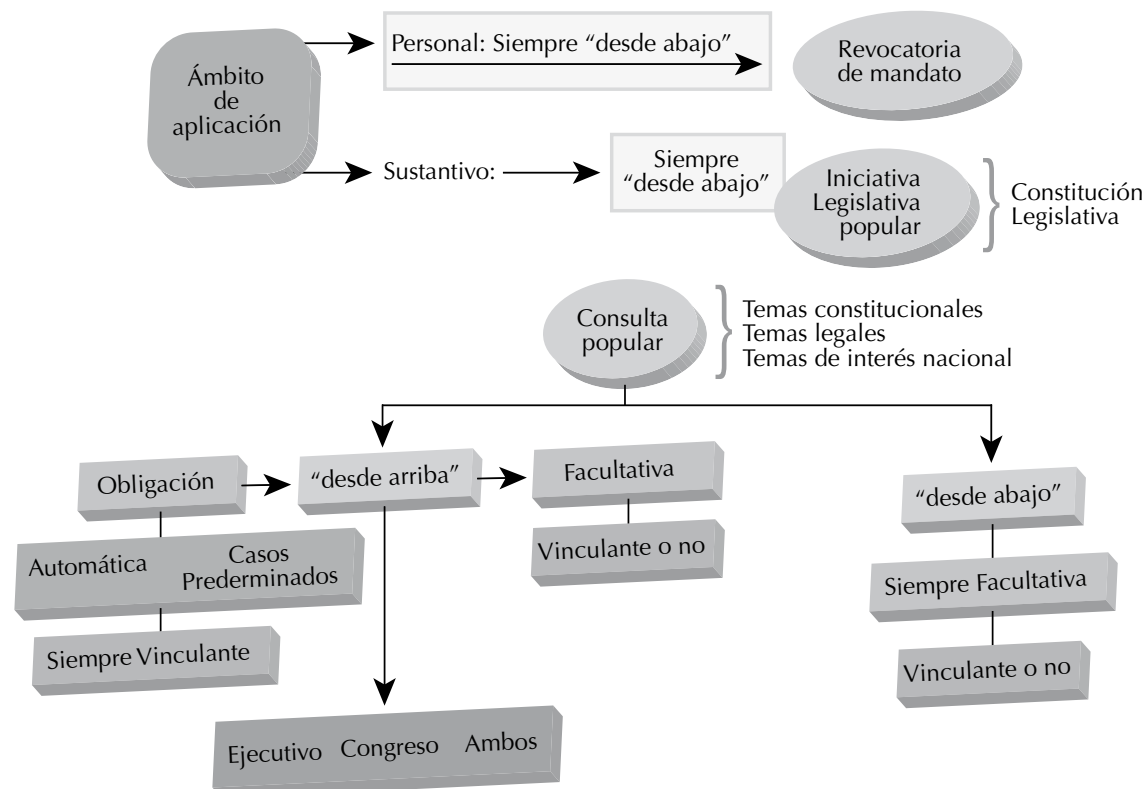

Consulta popular, plebiscito o referendo son términos que se utilizan indistintamente en los diferentes países de América Latina para referirse al más común y utilizado de los mecanismos de democracia directa. Si bien algunos distinguen entre plebiscito (consulta directa al pueblo sobre materias políticas de gran importancia) y referendo (consulta popular que versa sobre la aprobación de textos legales o constitucionales), en este trabajo empleamos el término "consulta popular" para referirnos indistintamente a ellos. Seguimos, en ese sentido, la posición de Santamaría Pastor y Biscaretti Di Ruffia, entre otros.

Por su naturaleza, la consulta popular puede ser obligatoria o facultativa. A su vez, la obligatoria puede dividirse en: a) obligatoria automática, en un caso previsto específicamente por la constitución, y b) obligatoria acotada a determinados procedimientos, sólo iniciados cuando surge una situación predefinida (por ejemplo, un conflicto entre el Ejecutivo y el Congreso no solucionable en el marco del sistema representativo).

Encontramos ejemplos de consulta obligatoria automática en países como Bolivia, Brasil, Colombia, Costa Rica, Ecuador, El Salvador, Guatemala, Panamá, Paraguay, Perú y Venezuela, donde determinadas decisiones que afectan a la soberanía nacional quedan sujetas a la decisión de los ciudadanos. En este sentido, en varios países se debe consultar el criterio de la población cuando se promueven iniciativas para modificar la división política administrativa del territorio o los distritos electorales. Ello incluye, según la Constitución Política de cada país, la creación de nuevas provincias, departamentos y/o distritos electorales; la autonomía 
regional o local; la aprobación de estatutos orgánicos regionales o locales, y los casos de unión de dos o más unidades territoriales o distritos electorales. Consultas populares automáticas en alguna de estas situaciones son posibles en Bolivia, Brasil, Colombia, Costa Rica, Ecuador, Perú y Venezuela.

En Bolivia además se realiza consulta popular de manera automática cuando se trate de aprobar tratados internacionales que refieran a aspectos específicamente definidos en la Constitución Política. De igual forma procede cuando se quiere convocar a una Asamblea Constituyente, situación que también es de consulta automática en Colombia y Ecuador. De manera similar, en Panamá la Constitución aprobada por la Asamblea Constituyente debe ser ratificada en referéndum para ser válida.

En El Salvador se convoca a consulta popular ante la posibilidad de conformar una república unida de los países del istmo centroamericano. En Guatemala, ante las regulaciones del diferendo territorial entre ese país y Belice, y en Panamá en los casos vinculados al destino del Canal de Panamá.

Con respecto a las consultas obligatorias de carácter acotado, éstas están presentes en Bolivia, Chile, Ecuador, Guatemala, Paraguay, Uruguay y Venezuela. En Chile se consultan las reformas constitucionales sólo si hay divergencia entre el Ejecutivo y el Parlamento. En Bolivia, Ecuador, Paraguay, Uruguay y Venezuela, de acuerdo con la Constitución, toda reforma constitucional (enmienda para el caso paraguayo) debe ser ratificada en última instancia mediante referendo. En Guatemala sólo necesitan ratificación popular las reformas constitucionales que realice el Congreso.

Por otra parte, las consultas facultativas (opcionales) también se pueden clasificar en dos grupos:

a) Cuando la iniciativa proviene desde arriba, es decir, cuando los órganos estatales tienen de manera exclusiva el derecho de poner en marcha el mecanismo. Éstas pueden provenir del Ejecutivo, del Congreso o de ambos de manera coordinada.

b) Cuando la iniciativa proviene desde abajo, es decir de la propia ciudadanía. En estos casos hace falta precisar cuál es la barrera a sortear (porcentaje o número mínimo de firmas de ciudadanos) para poner en marcha el mecanismo.

De los 16 países que regulan las consultas populares en la región, en 13 existe la posibilidad de realizar consultas facultativas ${ }^{3}$, que se pueden dividir con base en la legislación, según el origen de la iniciativa.

3 Los tres países que no tienen consultas facultativas de carácter nacional son Chile, El Salvador y Panamá. Como indicamos supra, en estos tres países sólo se pueden realizar consultas populares de carácter obligatorio. En Chile, sin embargo, la Constitución permite la consulta facultativa al nivel subnacional para aprobar la ley orgánica municipal. En Panamá la Constitución da a la ciudadanía el derecho a referéndum sólo en asuntos atribuidos a los Concejos. 
- Ejecutivo, Legislativo o el Pueblo: Bolivia, Costa Rica, Honduras, Nicaragua y Venezuela.

- Ejecutivo o Legislativo: Argentina, Guatemala y Paraguay.

- Ejecutivo o el Pueblo: Colombia, Ecuador ${ }^{4}$ y Perú ${ }^{5}$.

- Legislativo: Brasil.

- El Pueblo: Uruguay.

Por su carácter, los resultados de las consultas populares pueden ser vinculantes o no; en caso de ser vinculantes, con o sin exigencia de un quórum determinado. En el constitucionalismo comparado latinoamericano observamos que los procedimientos vinculantes se establecen para todas las consultas de tipo obligatorio y para las que suponen ratificar reformas constitucionales. Cabe advertir, empero, que la mayoría de los países de la región no asocian la validez de una consulta con un quórum determinado de la votación.

Las consultas contra leyes tienen carácter vinculante en Uruguay y Venezuela. En Ecuador, todas las consultas serán vinculantes y de inmediato cumplimiento. En Paraguay, el Congreso puede determinar que una consulta sea vinculante o no. En Argentina, el Congreso de la Nación, a iniciativa de la Cámara de Diputados, podrá someter a consulta popular vinculante todo proyecto de ley con excepción de aquellos cuyo procedimiento de sanción se encuentre especialmente reglado por la Constitución Nacional. La consulta no tiene carácter vinculante cuando la convoca exclusivamente el Poder Ejecutivo.

En Colombia tienen carácter vinculante cuestiones propuestas por el presidente con el acuerdo del Parlamento, o bien cuando participe una cuarta parte de los ciudadanos que componen el censo electoral en referendo para la derogatoria de una ley. En Honduras la consulta será vinculante si participa por lo menos el $51 \%$ de los ciudadanos inscritos en el Censo Nacional Electoral al momento de practicarse la consulta y si el voto afirmativo logra la mayoría de votos válidos; si el resultado no es afirmativo, la consulta sobre los mismos temas no podrá realizarse en el siguiente periodo de gobierno de la República. En Bolivia la ley del referendo estableció que los resultados de la consulta popular serían de vigencia inmediata y obligatoria, estableciéndose así su carácter vinculante. Por su parte, en Nicaragua en este sentido hay un vacío, ya que la Ley Electoral no dice expresamente que la consulta sea vinculante.

Por último, en Costa Rica los resultados serán vinculantes para el Estado si participa al menos el $30 \%$ de los ciudadanos inscritos en el padrón electoral para la legislación ordinaria,

4 De acuerdo con la nueva Constitución Política del Ecuador aprobada en referendo en agosto de 2008, los gobiernos autónomos descentralizados e incluso los ecuatorianos y ecuatorianas en el extranjero pueden convocar a consultas populares.

5 De manera genérica la Ley Orgánica de Elecciones, en el artículo 6, indica que el referéndum puede ser requerido por el Estado o la ciudadanía. 
y el $40 \%$ como mínimo para las reformas parciales de la Constitución y los asuntos que requieran aprobación legislativa por mayoría calificada.

Otro aspecto a destacar: en un buen número de países el campo de aplicación de las consultas populares se restringe mediante la exclusión de determinadas materias o con base a disposiciones positivas más o menos precisas, como en Bolivia, Honduras, Guatemala y Colombia. Por el contrario, en pocos países, entre ellos Argentina, Ecuador, Brasil y Nicaragua, no existen límites expresos al posible campo de aplicación de una consulta popular.

Por último, cabe señalar que sólo unos pocos países, entre ellos, Ecuador ${ }^{6}$, Colombia, Costa Rica, Uruguay y Venezuela cuentan con la institución del referendo abrogativo o sancionatorio, que otorga a los ciudadanos la posibilidad de revocar leyes surgidas del sistema representativo. En algunos países, sin embargo, determinadas materias, por ejemplo las políticas fiscal, monetaria y crediticia, o en el caso específico de Uruguay, aquellas privativas del Estado, quedan excluidas del campo de aplicación del referendo abrogativo.

El segundo mecanismo de democracia directa es la "iniciativa popular", entendiéndose por tal el derecho de la ciudadanía a proponer proyectos de ley y reformas legales o constitucionales, totales o parciales. Puede estar formulada o no formulada. La no formulada consiste en simples peticiones al Congreso a fin de que legisle sobre determinados asuntos; la iniciativa formulada va acompañada de un proyecto de ley. Si bien más de la mitad de los países de América Latina regulan estos mecanismos en sus diferentes modalidades, corresponde señalar su uso limitado, con la excepción de Uruguay y Colombia.

Por regla general, se trata de iniciativas legislativas populares ad parlamentum, ya que los proyectos de ley o reforma constitucional presentados son estudiados por el Parlamento, que toma la decisión al respecto sin consultar al electorado.

Sin embargo, algunos pocos países sí cuentan con una auténtica actividad legislativa de origen popular. Así, en Uruguay las iniciativas de reforma constitucional que provienen de la ciudadanía y que tengan el apoyo de al menos el $10 \%$ de los electores hábiles, deben someterse directamente a consulta popular. En Colombia, un proyecto de ley de iniciativa popular rechazado en el Parlamento debe someterse a "referendo aprobatorio" si así lo solicita el 10\% de los electores inscritos en el censo electoral. Es importante destacar, asimismo, el caso de Perú, donde la legislación prevé la posibilidad de someter a referendo una iniciativa legislativa rechazada o modificada sustancialmente por el Parlamento. Más recientemente en Ecuador la nueva Constitución dispone que si después de 180 días de análisis de la propuesta ciudadana en el órgano correspondiente no hubiese una decisión, dicha iniciativa entrará en vigencia. Cuando se trate de reforma constitucional si la función legislativa no aborda la propuesta en el plazo de un año, se podrá solicitar una consulta popular sin necesidad de cumplir con el $8 \%$ de respaldo electoral que se requiere para reformas constitucionales.

6 En Ecuador esta opción queda abierta mediante referéndum que la ciudadanía puede convocar para conocer cualquier asunto, según la Constitución Política. 
Finalmente, la "revocatoria de mandato" consiste en la facultad de dejar sin efecto el mandato del titular de un cargo de elección popular, resultado de un proceso de consulta del mismo tipo. Por lo general, en América Latina esta posibilidad queda limitada al ámbito subnacional salvo para los casos de Bolivia, Ecuador, Panamá y Venezuela, que sí lo contemplan a nivel nacional. En Bolivia todo cargo de elección popular podrá ser revocado siempre y cuando la convocatoria se realice después de la mitad del periodo por el cual fue electo y no durante el último año de gestión. En Ecuador, los ciudadanos pueden revocar el mandato a todas las autoridades de elección popular después del primer año y antes del último año del periodo para el que fueron elegidas. En Panamá, los partidos políticos pueden ejercer la revocatoria para invalidar el mandato de los diputados que hayan postulado, y los ciudadanos de un circuito electoral pueden hacerlo para revocar el mandato de los diputados de libre postulación (lo que no hace una revocatoria de mandato pura) ${ }^{7}$. En Venezuela, la revocatoria se establece para todos los cargos de elección popular, incluido el de Presidente de la República.

Hasta la fecha, la revocatoria de mandato sólo se ha empleado a nivel nacional en Venezuela, en agosto de 2004 cuando se sometió a consulta ciudadana la revocatoria del mandato del Presidente Hugo Chávez, y en agosto de 2008, en Bolivia, cuando igualmente se sometió a referendo revocatorio el mandato del Presidente Evo Morales, del vicepresidente y de los ocho prefectos departamentales. Sin embargo, este mecanismo también está regulado en varios países en el ámbito subnacional y se ha utilizado en algunas oportunidades en Perú, Bolivia y Colombia, entre otros.

El Cuadro 1 sistematiza de manera resumida, en tres categorías de países, la situación actual en materia de regulación y el uso de los mecanismos de democracia directa a nivel nacional. De la información se deriva que existe un primer grupo de países (12) en los que existe al menos uno de los tres mecanismos anteriormente citados, y éste o éstos han sido utilizados. El segundo grupo de países (4) lo constituyen aquellos que no han utilizado ninguno de los mecanismos pese a que disponen de regulación. El tercer grupo (2) reúne a los países que no prevén ninguno de estos mecanismos a nivel nacional.

En resumen, como ya hemos señalado en la introducción de este trabajo, a principios de los años 90 en América Latina cobró fuerza la tendencia de expandir los mecanismos de democracia directa en busca de mayores niveles de participación ciudadana para corregir la crisis de representación y hacer frente a los problemas de gobernabilidad.

Hasta marzo de 2010, como resultado de este proceso, 16 países de América Latina regulan a nivel nacional diferentes mecanismos de democracia directa en sus constituciones respectivas. Cabe advertir que la gran mayoría de las constituciones reformadas en la región durante las décadas de 1980 y 1990 incluyeron el uso de mecanismos de democracia directa. La razones para su adopción fueron diferentes en cada país, pero en varios casos se

7 En Panamá también existe la revocatoria para los Representantes de Corregimiento, y puede ser iniciada por iniciativa popular y por los partidos políticos cuando han sido postulados por éstos. 
CUADRO 1

Mecanismos de democracia directa en América Latina a nivel nacional

\begin{tabular}{|c|c|c|c|}
\hline PAÍS & $\begin{array}{l}\text { INICIATIVA } \\
\text { LEGISLATIVA } \\
\text { POPULAR }\end{array}$ & $\begin{array}{c}\text { CONSULTA POPULAR } \\
\text { (PLEBISCITO/REFERENDO) }\end{array}$ & $\begin{array}{l}\text { REVOCATORIA } \\
\text { DE MANDATO }\end{array}$ \\
\hline Argentina & Sí & Sí & No \\
\hline Bolivia & Sí & Sí & Sí, para todos los cargos \\
\hline Brasil & Sí & Sí & No \\
\hline Chile & No & $\begin{array}{l}\text { Sí, sólo para reforma constitucional } \\
\text { cuando hay desacuerdo entre } \\
\text { Ejecutivo y Congreso }\end{array}$ & No \\
\hline Colombia & Sí & Sí & No \\
\hline Costa Rica & Sí & Sí & No \\
\hline Ecuador & Sí & Sí & Sí, para todos los cargos \\
\hline Guatemala & Sí & Sí & No \\
\hline Panamá & Sí & Sí & $\mathrm{Si} \mathbf{i}^{8}$ \\
\hline Perú & Sí & Sí & $\mathrm{No}^{9}$ \\
\hline Uruguay & Sí & Sí & No \\
\hline Venezuela & Sí & Sí & Sí, para todos los cargos \\
\hline El Salvador & No & $\begin{array}{l}\text { Sí } \\
\text { No se ha utilizado }\end{array}$ & No \\
\hline Honduras & No & $\begin{array}{l}\text { Sí } \\
\text { No se ha utilizado }\end{array}$ & No \\
\hline Nicaragua & $\begin{array}{l}\text { Sí } \\
\text { No se ha utilizado }\end{array}$ & $\begin{array}{l}\text { Sí } \\
\text { No se ha utilizado }\end{array}$ & No \\
\hline Paraguay & $\begin{array}{l}\text { Sí } \\
\text { No se ha utilizado }\end{array}$ & $\begin{array}{l}\text { Sí } \\
\text { No se ha utilizado }\end{array}$ & No \\
\hline México & No & No & No \\
\hline Rep. Dominicana & No & No & No \\
\hline
\end{tabular}

Fuente: elaboración propia.

8 De acuerdo con el artículo 151 de la Constitución Política de Panamá, los partidos políticos pueden ejercer la revocatoria de mandato para destituir a los diputados que hayan postulado y los ciudadanos de un circuito electoral, para revocar el mandato de los diputados de libre postulación.

9 De acuerdo al artículo 2, literal a), de la Ley 26.300 y artículo 20 de la misma norma, existe la revocatoria del cargo de autoridades regionales y municipales. 
destacaron de manera significativa dos condiciones: la primera fue la creciente influencia de intereses de políticos alternativos (outsiders), entre ellos, presidentes neopopulistas o partidos anteriormente excluidos que llegaron a dominar las asambleas constituyentes, mientras que la segunda fueron circunstancias en las que los intereses políticos tradicionales sufrieron importantes presiones para democratizar las instituciones políticas. Uruguay constituye la excepción, ya que estos mecanismos datan de $1934^{10}$. Los países que han incorporado más recientemente estas figuras en sus constituciones son Costa Rica en mayo de 2002, Honduras en enero de $2004^{11}$ y reformados en Ecuador y Bolivia con las nuevas constituciones aprobadas en ambos países en 2008 y 2009, respectivamente.

Sólo dos de los 18 países de América Latina, República Dominicana y México, no contemplan en sus textos constitucionales estos mecanismos, aunque en el caso mexicano los instrumentos de democracia directa sí están regulados en algunos de sus estados o a nivel local. Finalmente, tenemos los casos de El Salvador, Honduras, Nicaragua y Paraguay, que sí los incluyen aunque no los han empleado hasta el presente. Colombia, por su parte, pese al amplio menú de mecanismos de democracia directa regulados en su Constitución de 1991, los ha utilizado escasamente en el ámbito nacional.

\section{EVOLUCIÓN Y ANÁLISIS DE LA EXPERIENCIA LATINOAMERICANA 1978-2010 EN EL USO DE LOS MECANISMOS DE DEMOCRACIA DIRECTA}

El Cuadro 2 presenta una visión sistematizada de la aplicación de consultas populares a nivel nacional en los países de la región durante el periodo 1978-marzo de 2010.

10 Sin embargo, a partir de la vigencia de la Constitución de 1919 se fueron adoptando algunos institutos de democracia directa a nivel local. En el Art. 141, por ejemplo, se consagraba el derecho de iniciativa sobre asuntos de una localidad si era apoyado por el $25 \%$ de los inscritos en una circunscripción.

11 El Congreso acordó reformar por adición el artículo 5 del Decreto Legislativo № 131 del 11 de enero de 1982, en el cual se instituyen como mecanismos de consulta a los ciudadanos el referendo y el plebiscito para asuntos de importancia fundamental de la vida nacional. Una ley especial aprobada por dos terceras partes de la totalidad de los diputados del Congreso Nacional determina los procedimientos, requisitos y demás aspectos necesarios para el ejercicio de las consultas populares (20 de enero de 2004). 


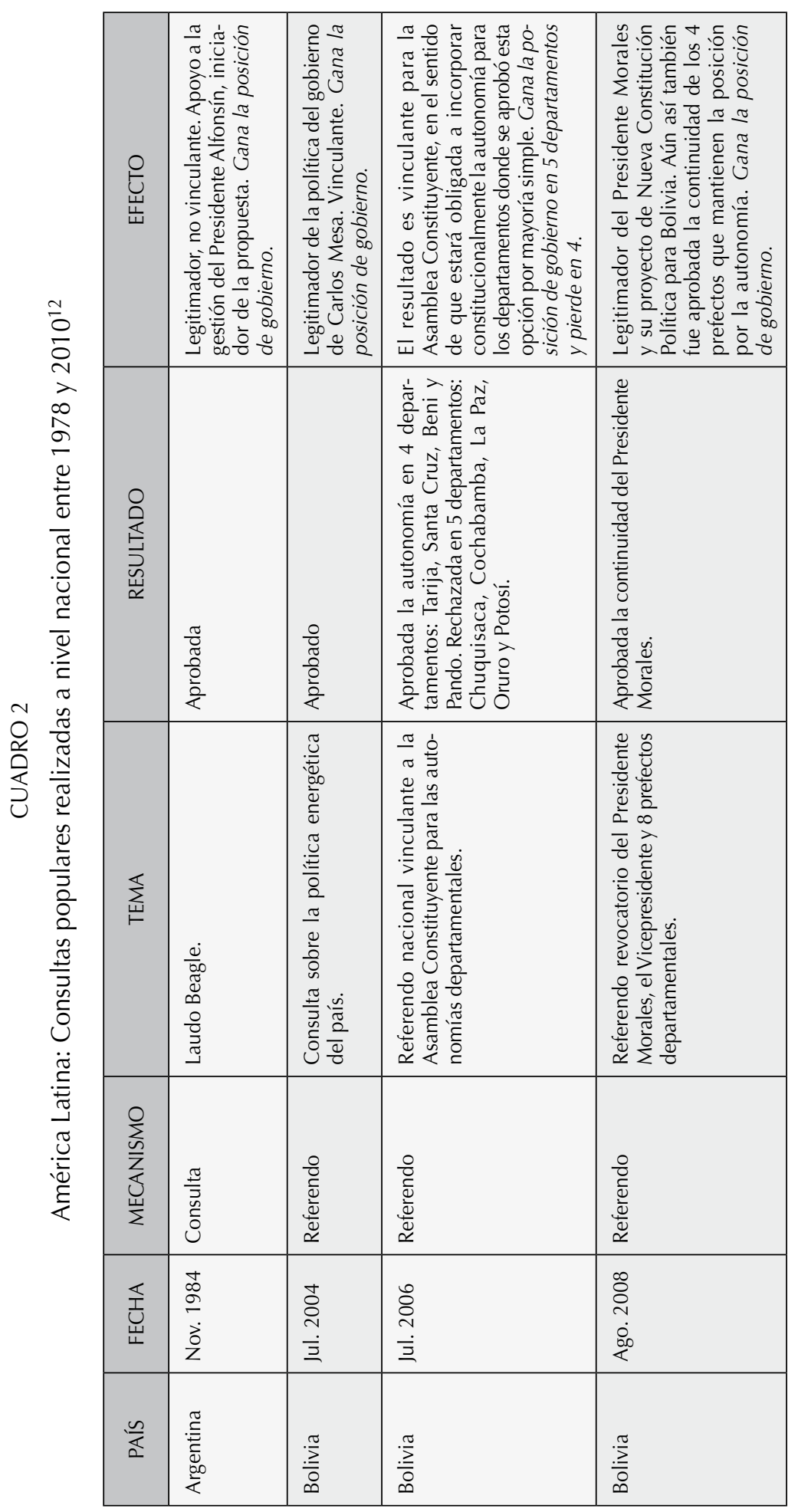

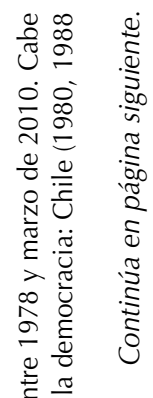

它 $\frac{\sigma}{\sigma}$

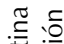

范

ชู류

选

वे

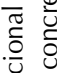

$\stackrel{\overbrace{}}{\check{0}}$

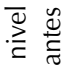

๘

흔

응후

폭

ปิ

응

ㅎํㅇ

동 ?

웡

ธิ है

촌

产

$\approx 0$

흠

()

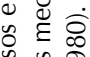

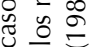

으 옹 त्ञ

응

잉

뜬

ए

ฉ.

ऽ ह ह

윤 음

娄

壬通 


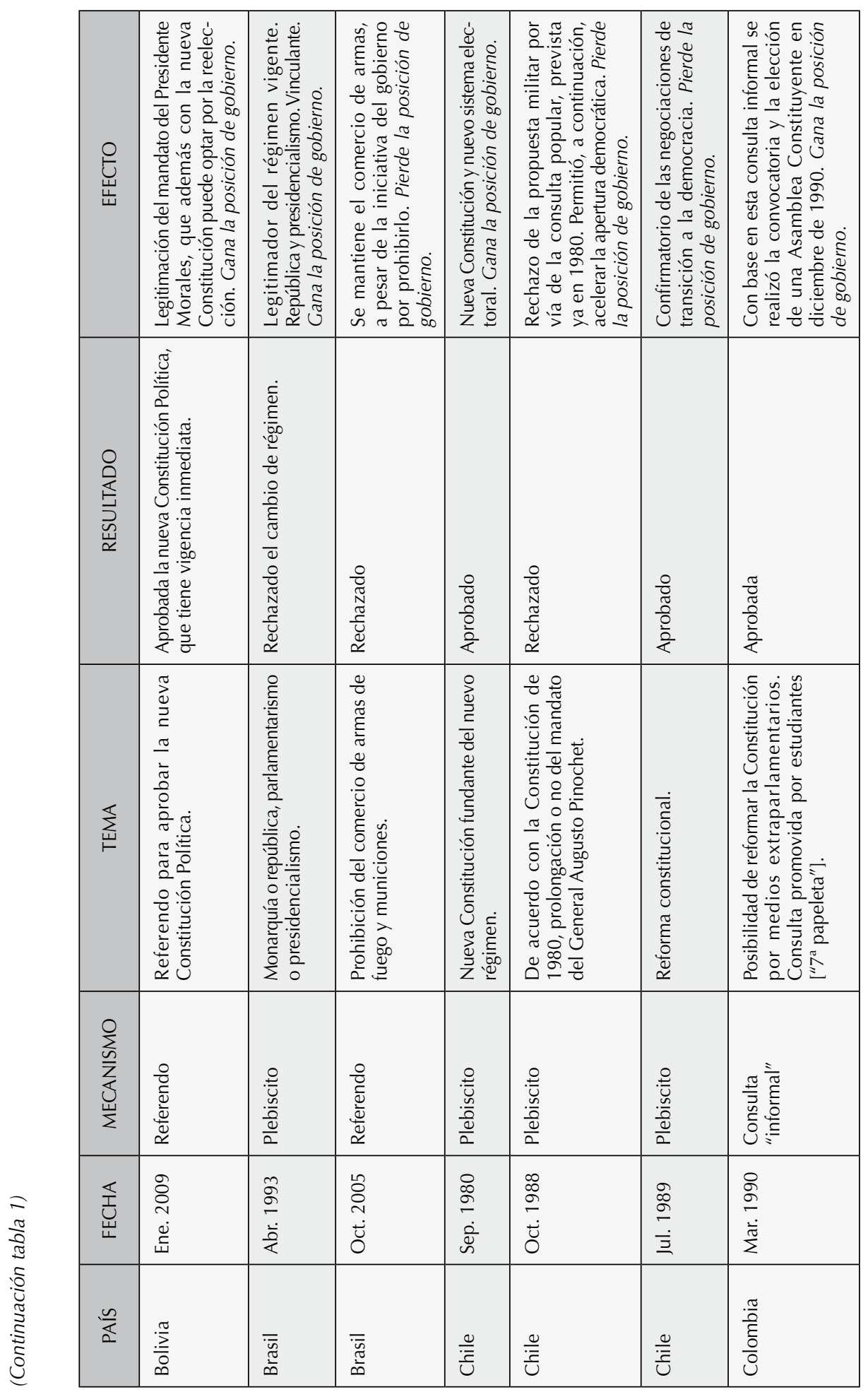




\begin{tabular}{|c|c|c|c|c|}
\hline 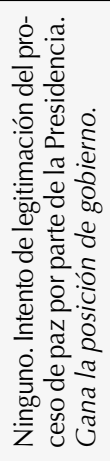 & 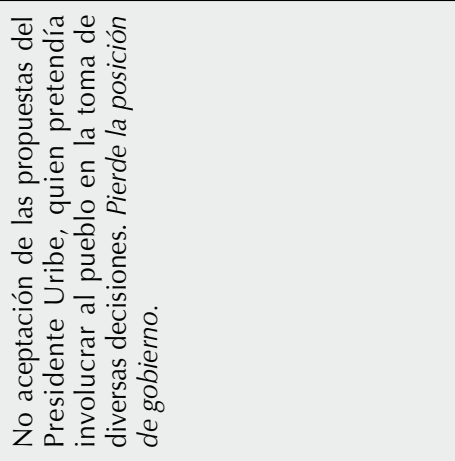 & 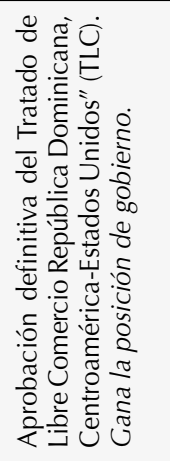 & 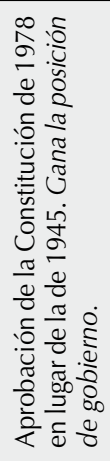 & 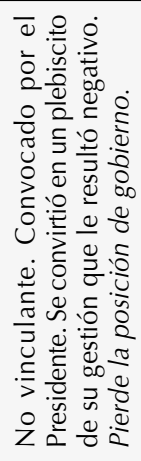 \\
\hline $\begin{array}{l}\frac{\pi}{0} \\
\frac{\pi}{0} \\
\frac{0}{0} \\
\frac{0}{<}\end{array}$ & 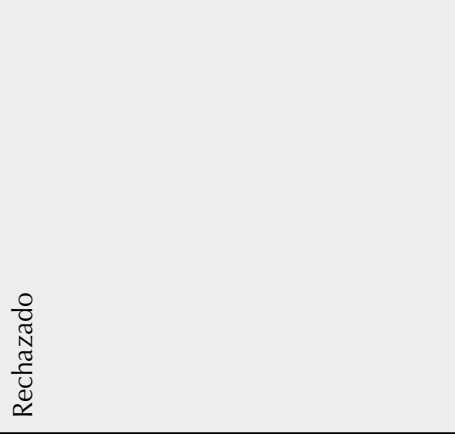 & $\begin{array}{l}\frac{0}{0} \\
\frac{\pi}{0} \\
\frac{0}{2} \\
\frac{0}{2}\end{array}$ & $\begin{array}{l}\frac{0}{0} \\
\frac{\pi}{0} \\
\frac{0}{0} \\
\frac{0}{2}\end{array}$ & 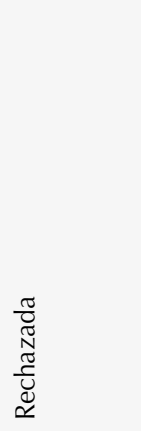 \\
\hline 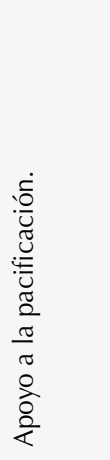 & 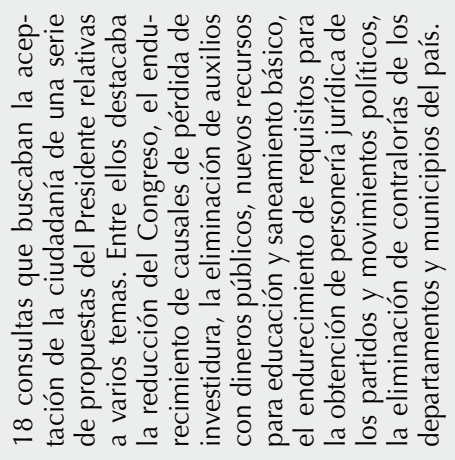 & 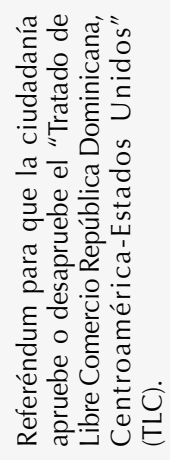 & 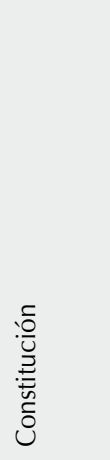 & 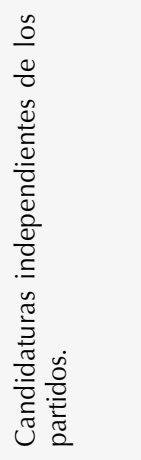 \\
\hline $\begin{array}{l}\frac{\pi}{5} \\
\bar{n} \\
0 \\
0\end{array}$ & 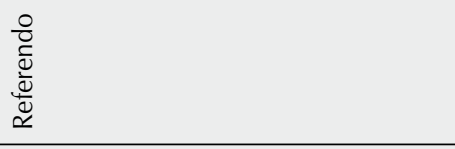 & 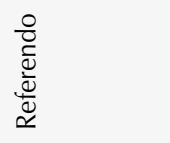 & $\begin{array}{l}\frac{0}{U} \\
\frac{0}{0} \\
\frac{0}{0} \\
\frac{0}{2}\end{array}$ & $\begin{array}{l}\frac{\pi}{5} \\
\overline{0} \\
0 \\
0\end{array}$ \\
\hline $\begin{array}{l}\hat{\sigma} \\
\text { Оे } \\
\text { ப் }\end{array}$ & 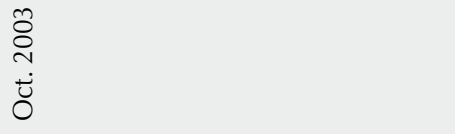 & 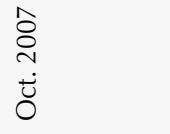 & 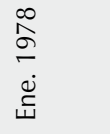 & 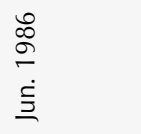 \\
\hline$\frac{\frac{\pi}{0}}{\frac{\frac{\pi}{0}}{0}}$ & $\frac{\frac{\pi}{0}}{\frac{0}{0}}$ & 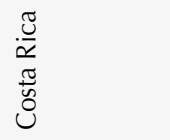 & $\begin{array}{l}\frac{\bar{o}}{0} \\
\frac{\pi}{\tilde{J}} \\
\text { D. }\end{array}$ & $\begin{array}{l}\frac{\overline{0}}{0} \\
\text { J } \\
\end{array}$ \\
\hline
\end{tabular}

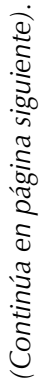




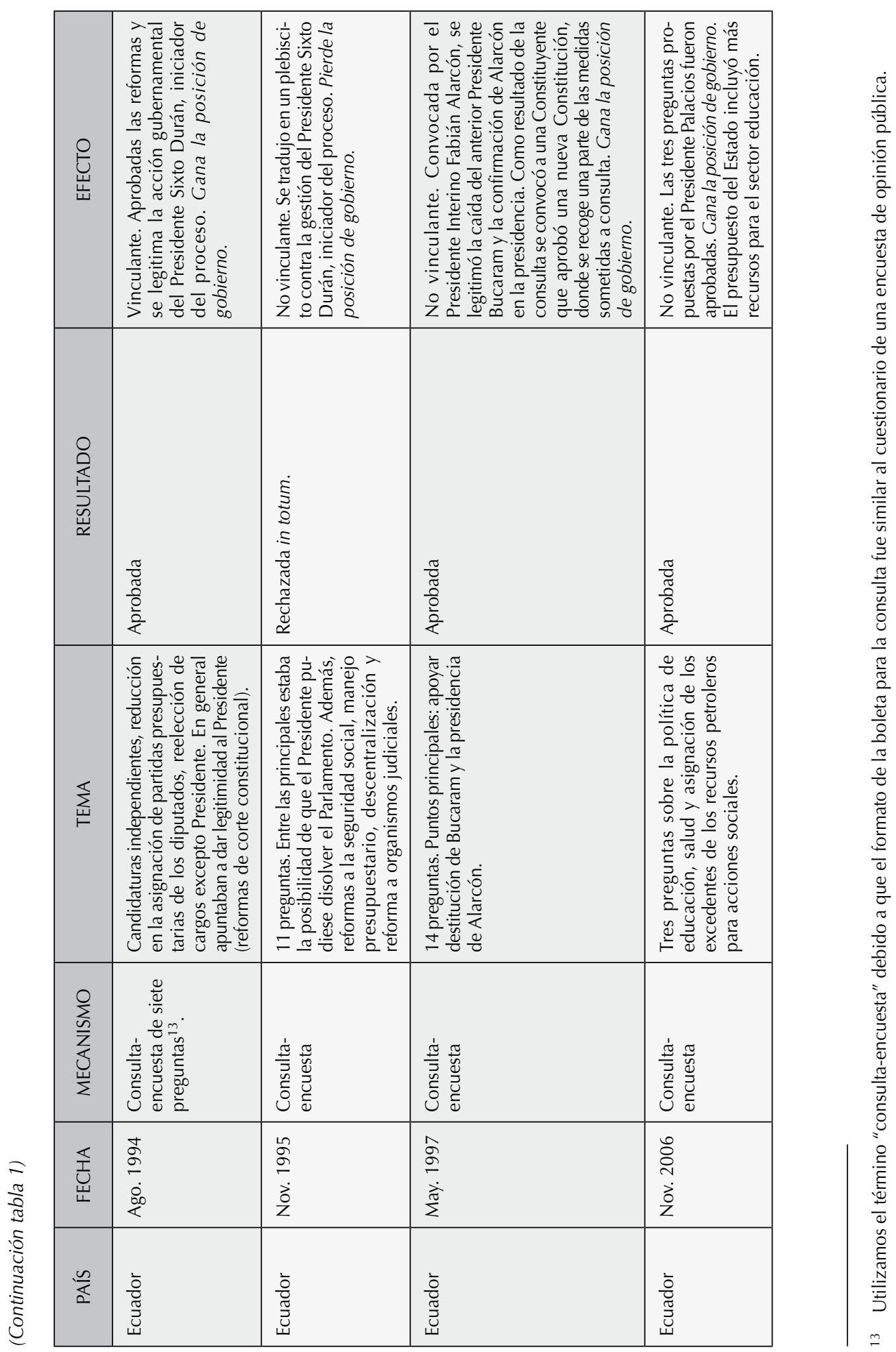




\begin{tabular}{|c|c|c|c|c|c|}
\hline 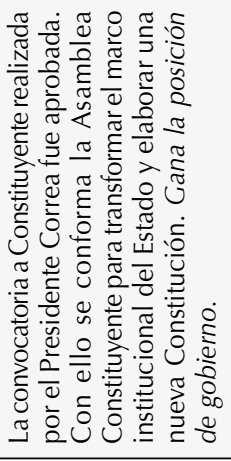 & 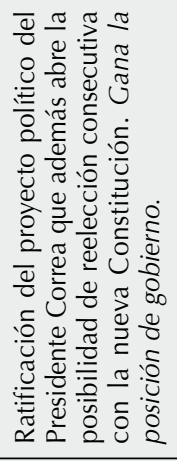 & 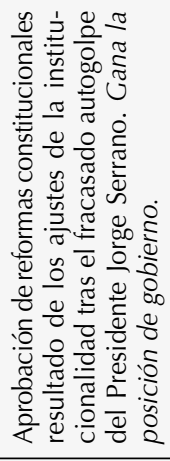 & 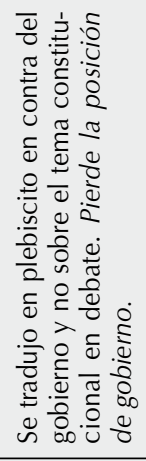 & 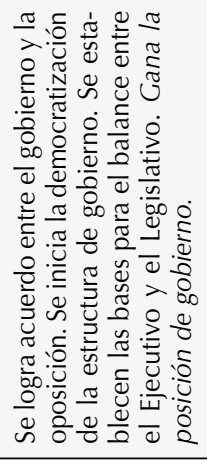 & 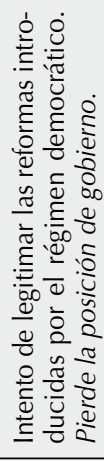 \\
\hline $\begin{array}{l}\frac{0}{0} \\
\frac{\pi}{0} \\
\frac{0}{2} \\
\frac{0}{2}\end{array}$ & $\begin{array}{l}\frac{\pi}{0} \\
\frac{\pi}{0} \\
\frac{0}{0} \\
\frac{0}{<}\end{array}$ & $\begin{array}{l}\frac{\pi}{0} \\
\frac{0}{0} \\
\frac{0}{0} \\
\frac{0}{2}\end{array}$ & $\begin{array}{l}\widetilde{\pi} \\
\mathbb{N} \\
\widetilde{J} \\
\widetilde{U} \\
\propto\end{array}$ & $\begin{array}{l}\frac{0}{0} \\
\frac{\pi}{0} \\
\frac{0}{2} \\
\frac{0}{2}\end{array}$ & 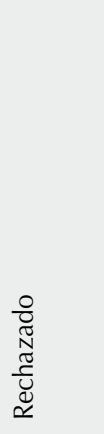 \\
\hline 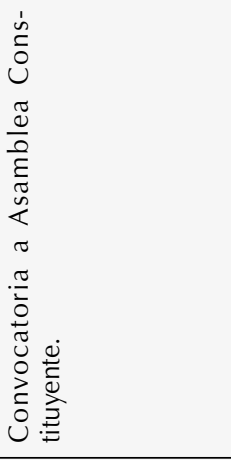 & 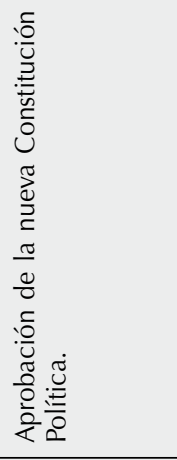 & 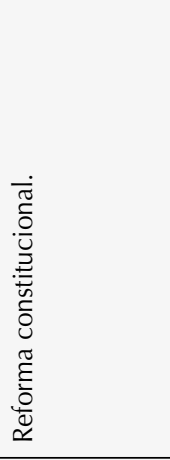 & 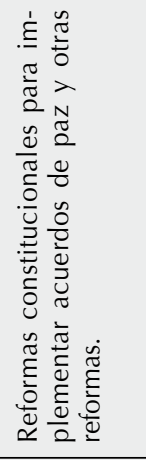 & 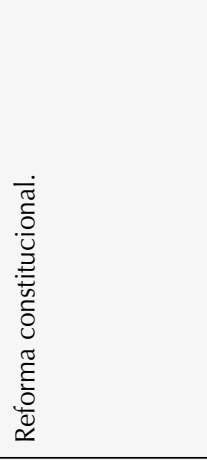 & 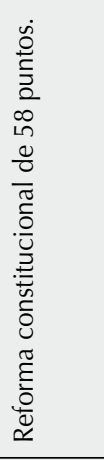 \\
\hline 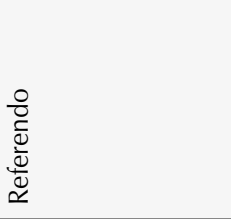 & 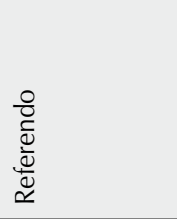 & 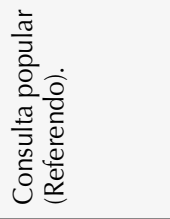 & 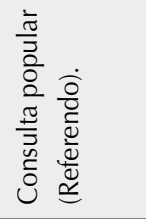 & 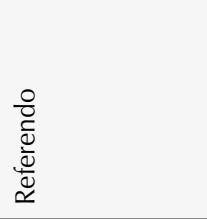 & 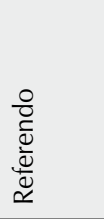 \\
\hline 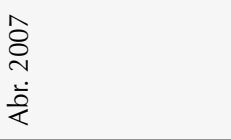 & 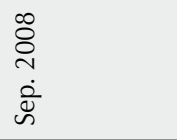 & 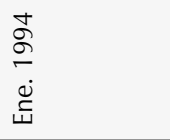 & $\begin{array}{l}\text { बे } \\
\stackrel{\sigma}{ } \\
\dot{\vec{\alpha}}\end{array}$ & $\begin{array}{l}\cong \\
\infty \\
\sigma \\
\stackrel{0}{*}\end{array}$ & 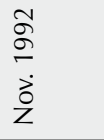 \\
\hline $\begin{array}{l}\stackrel{0}{0} \\
\stackrel{0}{\tilde{J}} \\
\end{array}$ & $\begin{array}{l}\overline{0} \\
\frac{\pi}{\tilde{J}} \\
\text { J }\end{array}$ & 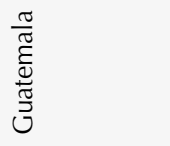 & 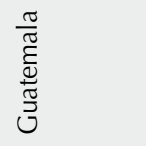 & 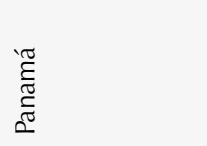 & 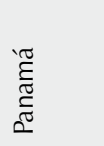 \\
\hline
\end{tabular}

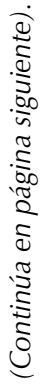




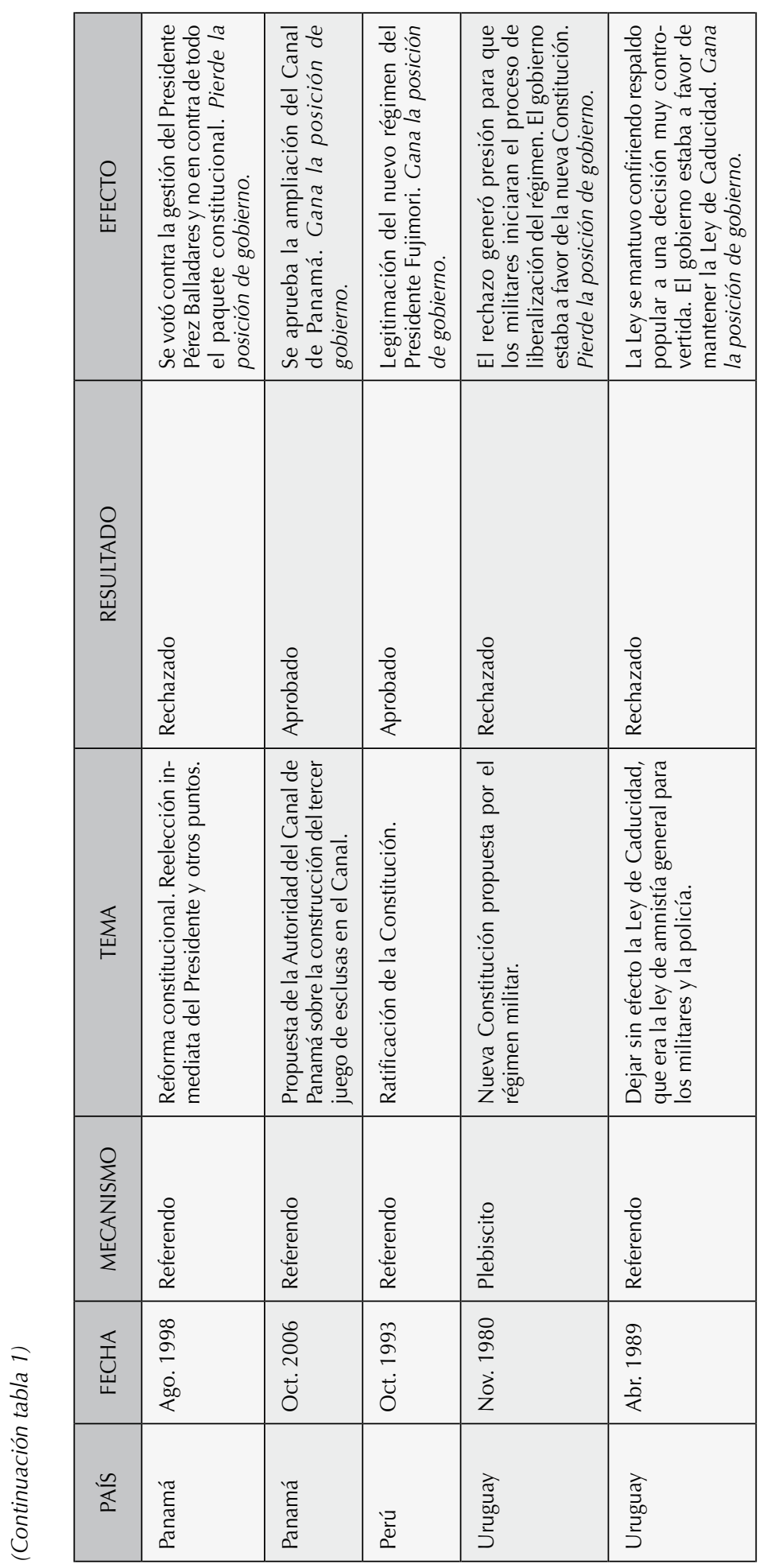




\begin{tabular}{|c|c|c|c|c|c|c|c|}
\hline 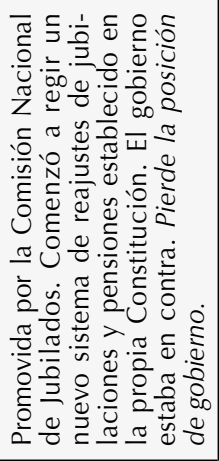 & 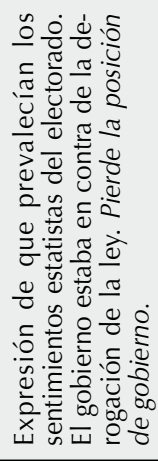 & 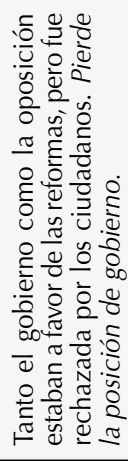 & 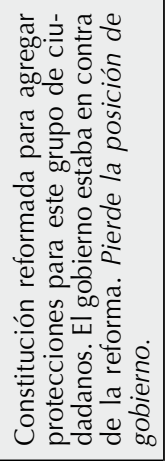 & 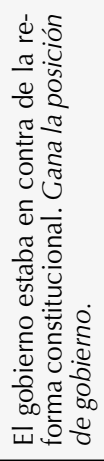 & 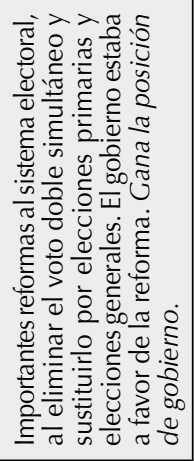 & 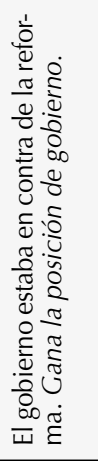 & 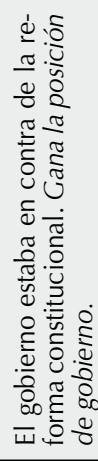 \\
\hline $\begin{array}{l}\frac{0}{0} \\
\frac{\pi}{0} \\
\frac{0}{2} \\
\frac{0}{<}\end{array}$ & $\begin{array}{l}\frac{0}{0} \\
\frac{\pi}{0} \\
\frac{0}{2} \\
\frac{0}{<}\end{array}$ & 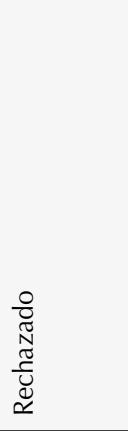 & $\begin{array}{l}\frac{0}{0} \\
\frac{\pi}{0} \\
\frac{0}{2} \\
\frac{0}{2}\end{array}$ & 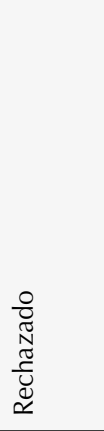 & $\begin{array}{l}\frac{0}{0} \\
\frac{\pi}{0} \\
\frac{0}{2} \\
<\end{array}$ & 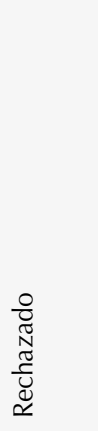 & 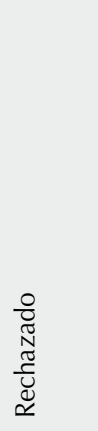 \\
\hline 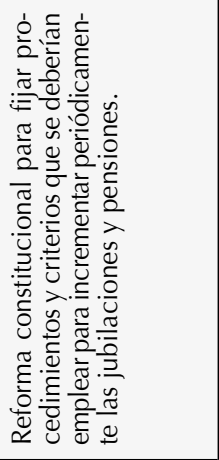 & 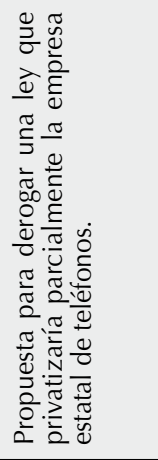 & 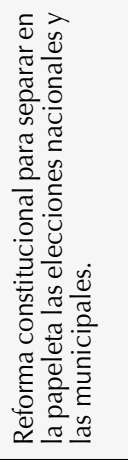 & 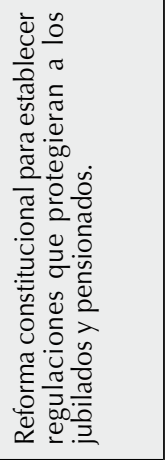 & 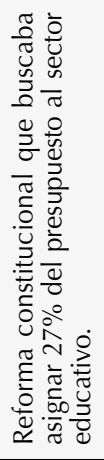 & 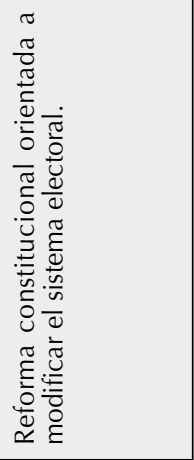 & 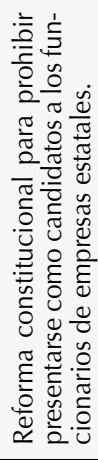 & 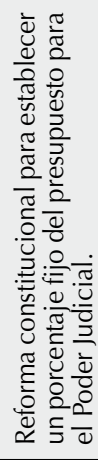 \\
\hline $\begin{array}{l}\frac{0}{0} \\
. \frac{0}{0} \\
\frac{.0}{0} \\
\frac{0}{2} \\
\end{array}$ & 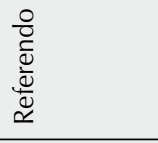 & $\begin{array}{l}\frac{0}{U} \\
\frac{.0}{0} \\
\frac{0}{0} \\
\end{array}$ & $\begin{array}{l}\frac{0}{U} \\
\frac{.0}{0} \\
\frac{0}{0} \\
\alpha\end{array}$ & $\begin{array}{l}\frac{0}{U} \\
\frac{.0}{0} \\
\frac{0}{0}\end{array}$ & $\begin{array}{l}\frac{0}{U} \\
\frac{.0}{0} \\
\frac{0}{0} \\
\end{array}$ & $\begin{array}{l}\frac{0}{0} \\
\frac{.0}{0} \\
\frac{0}{0}\end{array}$ & $\begin{array}{l}\frac{0}{U} \\
\frac{.0}{0} \\
\frac{0}{0} \\
\end{array}$ \\
\hline $\begin{array}{l}\text { ᄋ } \\
\circ \\
\circ \\
\dot{0} \\
\text { ż }\end{array}$ & $\begin{array}{l}\text { مू } \\
\stackrel{\circ}{0} \\
\dot{0}\end{array}$ & 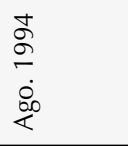 & $\begin{array}{l}\text { ठ } \\
\text { Оे } \\
\dot{0} \\
z\end{array}$ & $\begin{array}{l}\text { ठे } \\
\text { o } \\
\text { ठे } \\
\text { z }\end{array}$ & 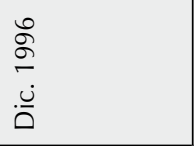 & 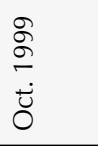 & 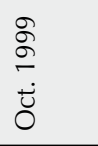 \\
\hline 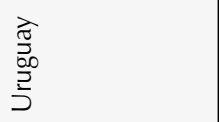 & 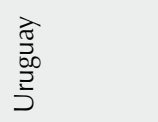 & 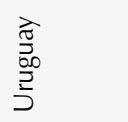 & 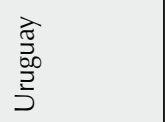 & 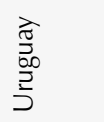 & 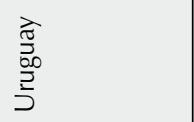 & 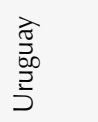 & 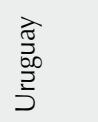 \\
\hline
\end{tabular}




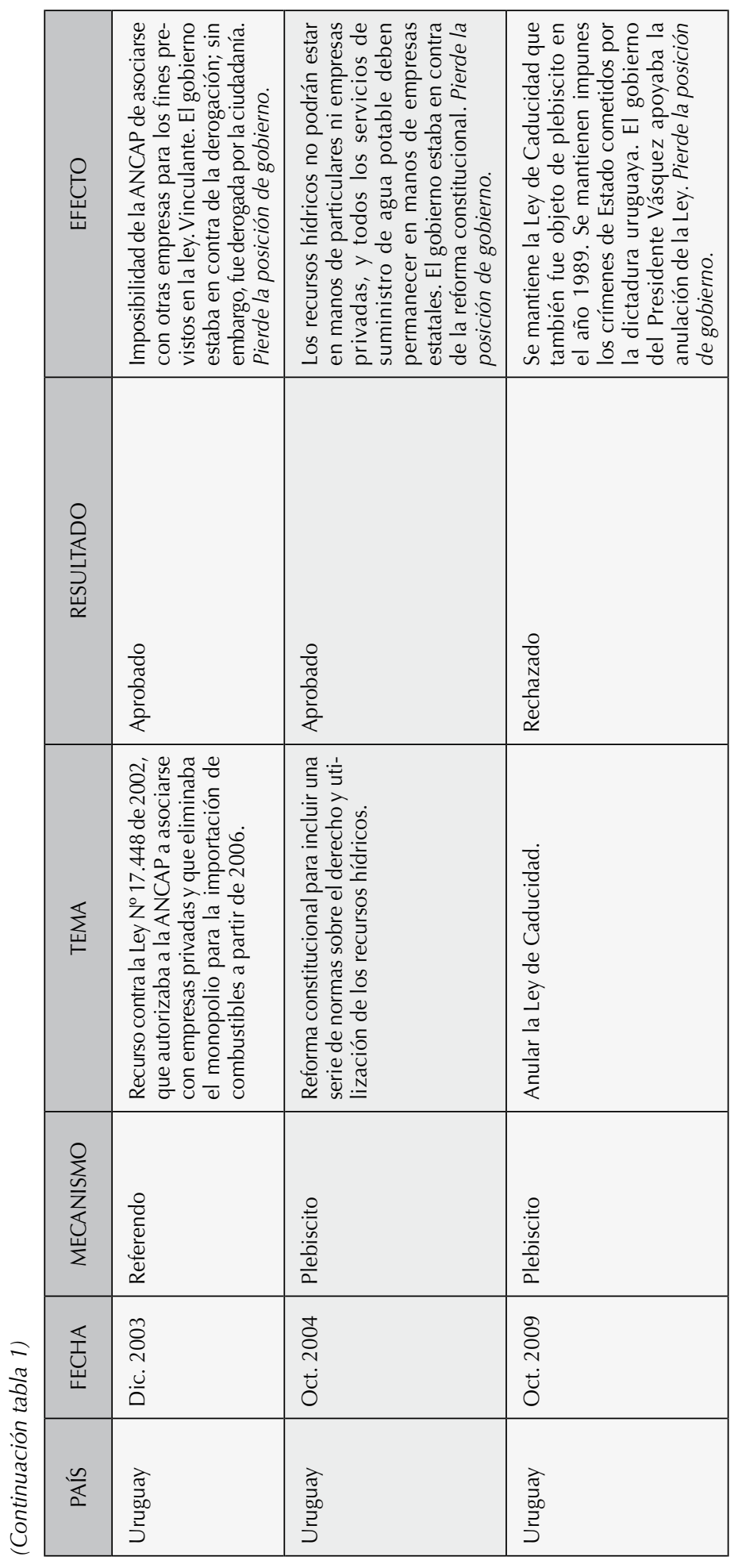




\begin{tabular}{|c|c|c|c|c|c|c|}
\hline 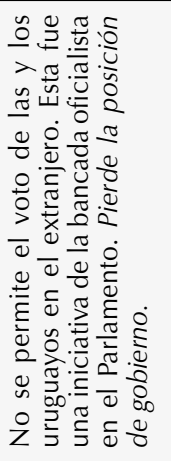 & 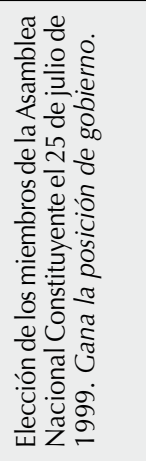 & 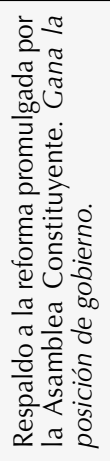 & 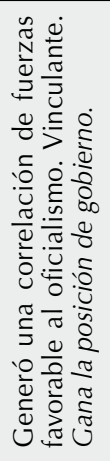 & 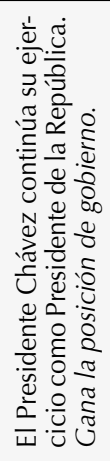 & 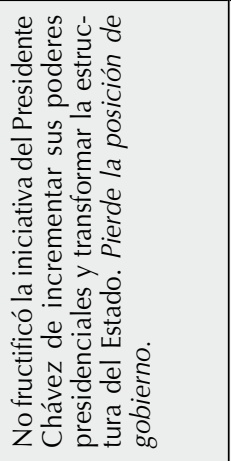 & 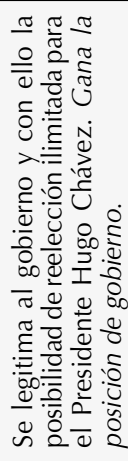 \\
\hline 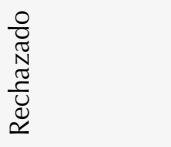 & $\begin{array}{l}\frac{0}{0} \\
\frac{\pi}{0} \\
\frac{0}{0} \\
\frac{0}{2}\end{array}$ & $\begin{array}{l}\frac{0}{0} \\
\frac{\pi}{0} \\
\frac{0}{0} \\
\frac{0}{2}\end{array}$ & $\begin{array}{l}\frac{0}{0} \\
\frac{\pi}{0} \\
\frac{0}{0} \\
\frac{0}{2}\end{array}$ & 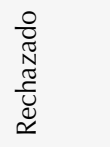 & 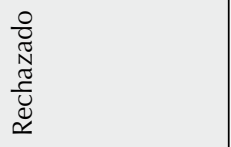 & $\begin{array}{l}\frac{0}{0} \\
\frac{\pi}{0} \\
\frac{0}{0} \\
\frac{0}{2}\end{array}$ \\
\hline 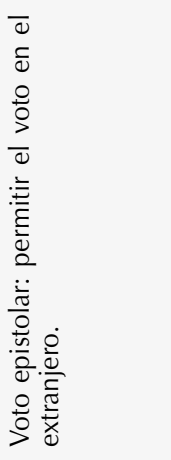 & 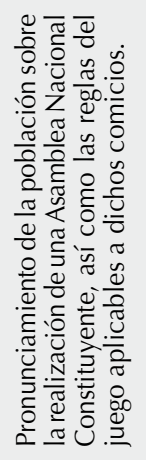 & 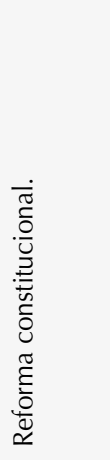 & 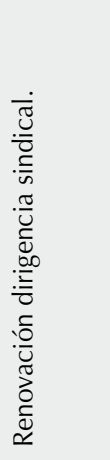 & 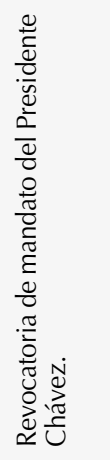 & 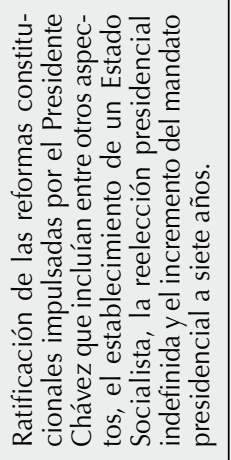 & 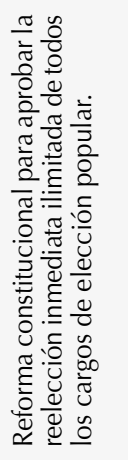 \\
\hline $\begin{array}{l}\frac{0}{0} \\
. \frac{n}{0} \\
\frac{0}{0} \\
\end{array}$ & 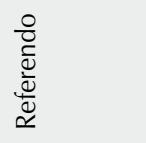 & 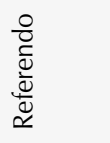 & 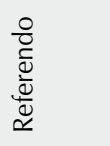 & 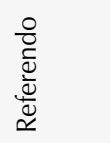 & 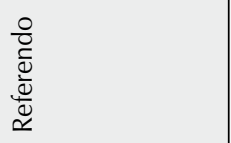 & 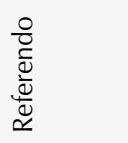 \\
\hline 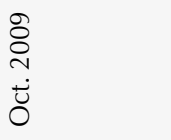 & 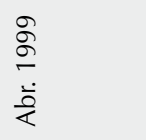 & $\begin{array}{l}\stackrel{\mathscr{\sigma}}{\sigma} \\
\stackrel{\dot{v}}{0}\end{array}$ & $\begin{array}{l}\stackrel{8}{8} \\
\stackrel{\sim}{1} \\
\dot{u} \\
\dot{0}\end{array}$ & 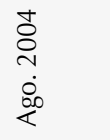 & $\begin{array}{l}\hat{\delta} \\
\text { v } \\
\dot{u} \\
\dot{0}\end{array}$ & $\begin{array}{l}\stackrel{8}{8} \\
\stackrel{2}{ } \\
\dot{0} \\
\dot{0}\end{array}$ \\
\hline 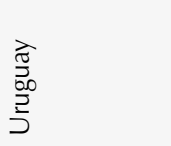 & 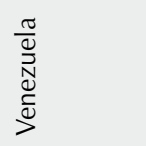 & $\begin{array}{l}\frac{\pi}{U} \\
\stackrel{N}{N} \\
\mathbb{U} \\
\stackrel{D}{J}\end{array}$ & $\begin{array}{l}\frac{\pi}{U} \\
\stackrel{N}{N} \\
\mathbb{U} \\
\stackrel{J}{J}\end{array}$ & 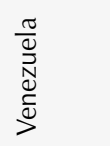 & 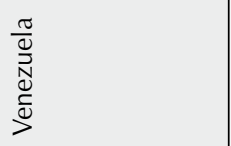 & 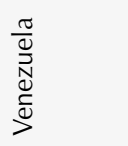 \\
\hline
\end{tabular}


Como claramente se desprende del Cuadro 2, entre 1978 y marzo de 2010 se Ilevaron a cabo un total de 49 consultas populares ${ }^{14}$ en 12 países de la región. En 30 ocasiones (61\%), la posición del gobierno salió vencedora en el resultado de las consultas y en las otras 19, la posición del gobierno fue derrotada. El país donde más veces la tesis oficialista fue derrotada es el Uruguay con nueve de las catorce consultas celebradas, o sea, un 64\%. Por su parte, si analizamos los resultados de las 19 consultas celebradas desde el año 2000 a la fecha, vemos que en 12 ocasiones triunfó la tesis del gobierno (o sea, el 63\% de los casos), cuatro veces en Bolivia, en el 2004, 2006, 2008 y 2009; tres veces en el Ecuador, en el 2006, 2007 y 2008; tres veces en Venezuela, en el 2000, 2004 y 2009; una vez en Costa Rica en el 2007, y una en Panamá, en el 2006. Por su parte, la tesis del gobierno fue derrotada en siete ocasiones desde el 2000 a la fecha (o sea, en el 37\% de los casos): cuatro veces en el Uruguay, en el 2003, 2004 y dos veces en el 2009; una en Colombia, en el 2003; una en Brasil en el 2005, en la cual el gobierno de Lula trató de jugar de manera ambivalente para despegarse de la derrota que sufrió la propuesta que en un principio apoyó su gobierno, y una en Venezuela en el 2007, cuando se rechazaron las reformas constitucionales impulsadas por el Presidente Chávez.

Es significativo el hecho de que cinco de las 49 consultas hayan tenido lugar durante regímenes autoritarios: Uruguay en 1980; Chile en 1980, 1988 y 1989, y Panamá en 1983. En este último, el referendo aprobado en 1983 fue producto del consenso entre gobierno y oposición, y las reformas constitucionales aprobadas, cuya mayoría continúa vigente, configuraron el punto de partida para reequilibrar al Ejecutivo y Legislativo y democratizar la estructura del gobierno panameño. Por su parte, los resultados del plebiscito celebrado en Uruguay en 1980 no favorecieron a los militares y allanaron el camino a cuatro años de negociaciones que culminaron con la reinstauración de la democracia. Por el contrario, el régimen del General Augusto Pinochet se impuso en Chile en el plebiscito de 1980 e introdujo su propia Constitución. Sin embargo, la consulta popular celebrada en 1988, prevista en la Constitución de 1980 como un instrumento para validar la continuidad de Pinochet, tuvo un resultado desfavorable para el régimen. Posteriormente, la consulta popular de 1989, cuyo propósito fue modificar la Constitución para promover el retiro de Pinochet del poder y facilitar la transición a la democracia, consiguió un resultado positivo.

Un análisis desde la perspectiva del carácter vinculante o no de las consultas populares muestra que las realizadas en Argentina en 1984, Colombia en 1990 y 1997 y Ecuador en 1986, 1995, 1997 y 2006 no tuvieron carácter vinculante. En el último país, la consulta de 1997 condujo a la convocatoria de una Asamblea Constituyente, que incorporó en su propuesta de reforma Constitucional buena parte de lo que se había aprobado previamente mediante la consulta popular. En los restantes 42 casos el resultado de la consulta fue vinculante.

14 En Brasil se han realizado dos referéndums más que no se toman en cuenta, pues no fueron "oficiales". Se trata del referéndum de septiembre de 2000 sobre las reformas del Fondo Monetario Internacional, y el segundo en septiembre del 2002 sobre el Área de libre comercio de las Américas. Asimismo, en el 2008 en Bolivia se realizaron los referéndum para la autonomía de cuatro Departamentos, sin embargo no se incluyen por no ser reconocidos por la Corte Nacional Electoral. 
Se observa, asimismo, una variada gama de contenidos y resultados en la temática de las consultas. Así, por ejemplo, 23 de las consultas populares se realizaron para aprobar o rechazar reformas constitucionales (o sea, el 47\%): nueve en Uruguay, cinco rechazadas y cuatro aprobadas; tres en Panamá, de las cuales dos se rechazaron y una se aprobó; tres en Venezuela, dos aprobadas y una rechazada; dos en Chile, ambas aprobadas; dos en Ecuador, ambas aprobadas; dos en Guatemala, una aprobada y una rechazada; una en Brasil, rechazada, y una celebrada en Perú aprobada. Asimismo, dos consultas han sido expresamente para aprobar y poner en vigencia nuevas constituciones políticas; tal es el caso de Ecuador en el 2008 y Bolivia en el 2009.

Las restantes 24 consultas trataron sobre diversos temas. La de Argentina de 1984 sobre el conflicto del Canal de Beagle; en Bolivia, la consulta realizada en 2004 aprobó la política del gobierno en materia energética, el referendo autonómico de 2006 sometió a consideración de la ciudadanía la autonomía de los departamentos del país, y en 2008 el Presidente Morales asegura su continuidad después del referendo revocatorio al que se sometió. La consulta efectuada en Brasil en octubre de 2005 para prohibir el comercio de armas de fuego y municiones fue rechazada; la de Colombia de 1990 legitimó y conformó una Asamblea Constituyente el mismo día de su realización; en 1997, una segunda consulta buscó el apoyo a los esfuerzos de paz por parte de la Presidencia, y el referendo de 2003 sometió a consideración de la ciudadanía una serie de propuestas del Presidente Uribe referidas a diversos temas, entre ellos la reducción del Congreso, el endurecimiento de las causales de pérdida de investidura, la eliminación de auxilios con dineros públicos y la dotación de nuevos recursos para la educación, entre otros. Las propuestas del Presidente fueron rechazadas por la ciudadanía.

Como ya tuvimos ocasión de señalar, en Chile se sometió a plebiscito en 1988 la continuidad del General Augusto Pinochet; el resultado fue negativo y con ello se aceleró el proceso de apertura democrática. En Costa Rica, el referendo de octubre de 2007 aprobó el Tratado de Libre Comercio República Dominicana, Centroamérica y Estados Unidos. En Ecuador se realizaron cinco consultas: la de 1986 rechazó la posibilidad de las candidaturas independientes; en 1995 otra consulta-encuesta negó, entre otras cosas, la autoridad del Presidente para disolver el Parlamento y la ampliación de dos a cuatro años del periodo a los legisladores provinciales. La tercera consulta-encuesta se realizó en 1997, cuando se legitimó la destitución del Presidente Abdalá Bucaram y la confirmación de su sucesor Fabián Alarcón. La cuarta se efectuó en noviembre de 2006 y se aprobaron tres preguntas sobre la política de educación, salud y asignación de los excedentes de los recursos petroleros para acciones sociales. En la quinta y última, realizada en abril de 2007, se aprobó la convocatoria a una Asamblea Constituyente.

En 2006 se llevó a cabo el referendo en Panamá con el objetivo de autorizar la construcción del tercer juego de esclusas en el Canal. En Uruguay, cinco consultas celebradas en 1989, 1992, 2003 y dos en el 2009 buscaban anular determinada legislación; la primera y las últimas dos fueron rechazadas y se mantuvo la ley. En los otros dos casos (1992 y 2003) se derogaron las leyes en cuestión. En Venezuela, la consulta de abril de 1999 aprobó la conformación de una Asamblea Constituyente; asimismo, en diciembre de 2000 el gobierno del Presidente Hugo Chávez convocó a otro referendo para sondear el apoyo a la convocatoria 
a nuevas elecciones sindicales en un lapso de 180 días. Como la convocatoria para resolver un asunto de esta materia entraba en conflicto con las disposiciones de la Organización Internacional del Trabajo, la ciudadanía respondió a la petición de los sindicatos de no participar; sin embargo, la iniciativa fue aprobada con la afluencia a las urnas de sólo 23,5\% del electorado. Finalmente, la consulta convocada en 2004 con el objetivo de revocar el mandato del Presidente Chávez ratificó su continuación en el Ejecutivo.

Corresponde destacar, en cuanto al origen de las consultas populares, que la amplia mayoría de las realizadas durante el periodo 1978-marzo de 2010 resultó de iniciativas surgidas "desde arriba". En efecto, el Poder Ejecutivo promovió las consultas de Argentina en 1984, Bolivia en 2004 y 2008, Brasil en $2005^{15}$, Colombia en 1997 y 2003, Costa Rica en 2007, Venezuela en 2000, y las siete consultas de Ecuador. En total, 15 casos.

Las aprobaciones de reformas constitucionales o nuevas constituciones, si bien formalmente iniciadas por los órganos legislativos y/o constituyentes, también fueron promovidas por el Ejecutivo en 11 casos: Bolivia 2009; Ecuador 2008; Guatemala en 1994; Panamá en 1998; Perú en 1993; Venezuela en 1999, 2007 y 2009; Chile y Uruguay en 1980 durante los regímenes militares y más recientemente la iniciativa de voto epistolar en el 2009 en el Uruguay. En síntesis, el Ejecutivo en conjunto con el Legislativo inició 26 de las 49 consultas realizadas. Otras 10 nacieron de acuerdos de la clase política plasmados en constituciones aprobadas o rechazadas, o resultaron de previsiones constitucionales previamente pactadas, como la ya citada consulta brasileña de 1993, la chilena de 1988 y los referendos en Panamá de 1983 y 2006. En total, 36 de las consultas se llevaron a cabo con base en iniciativas "desde arriba".

Los restantes 13 casos partieron de iniciativas "desde abajo". 10 en Uruguay: tres reformas constitucionales aprobadas (en 1989, 1994 y 2004), tres rechazadas (una en 1994 y dos en 1999) y cuatro plebiscitos convocados para revocar leyes. La decimoprimera, como ya se señaló, tuvo lugar en Colombia en 1990, con carácter informal y dio origen a la nueva Constitución de 1991; la decimosegunda en Venezuela (agosto de 2004), impulsada por sectores de la oposición que promovieron el proceso de recolección de firmas requerido para solicitar que se convocara a la revocatoria de mandato. Por último, la decimotercera, en Bolivia en 2006, cuando las más importantes organizaciones de Santa Cruz de la Sierra reunieron las firmas necesarias para realizar el referendo sobre las autonomías departamentales del país.

\section{BALANCE}

\subsection{Uso y frecuencia de la aplicación de las consultas populares}

Un buen diseño y uso de los instrumentos de democracia directa puede generar una sana renovación de un orden sociopolítico, capacitar al ciudadano para participar en los

15 Vale la pena aclarar que la consulta popular de Brasil en el 2005 fue convocada por el Poder Legislativo, y promovida por el Poder Ejecutivo. 
asuntos públicos y ejercer controles eficaces sobre los funcionarios electos, y complementar adecuadamente la democracia representativa con eficaces fórmulas de participación directa (Kornblith, 2007: 8). Sin embargo, si estos mecanismos de democracia directa son utilizados de manera patológica o desvirtuada, los mismos pueden también constituirse en un instrumento peligroso para la puesta en marcha de una "democracia plebiscitaria".

En este sentido, el análisis de la experiencia latinoamericana comparada en materia de mecanismos de democracia directa de los últimos 32 años evidencia, en mi opinión, que el uso de estos instrumentos a escala nacional ha sido más bien modesto y altamente concentrado en un número reducido de países. En efecto, estas instituciones han sido utilizadas sólo en 12 de los 16 países que regulan estos mecanismos (todos en democracia a excepción de Chile, Uruguay en un caso -1980- y Panamá en un caso también -1983-), pero de manera frecuente sólo en dos de ellos (Uruguay y Ecuador) ${ }^{16}$. En Venezuela, por su parte, se han utilizado con mucha mayor frecuencia desde la llegada al poder del Presidente Chávez; situación similar ocurre con Bolivia desde la llegada de Evo Morales. Por otro lado, en Panamá, con el referendo de 2006, las experiencias de esta práctica han sido cuatro. De este modo, 36 de los 49 procesos (o sea, el 73\%), han tenido lugar sólo en cinco países: 14 en el Uruguay, ocho en Ecuador, seis en Venezuela, cuatro en Bolivia y otros cuatro en Panamá. Para decirlo en términos cuantitativos, el 27\% de los 18 países de la región concentra el $73 \%$ de las consultas o procesos de democracia directa que han tenido lugar entre 1978 y marzo de 2010, y un solo país, Uruguay, concentra el 29\% del total de estas consultas.

Cabe señalar que una mirada retrospectiva desde el inicio de la transición a la democracia (finales de 1970) a la fecha, evidencia una tendencia creciente al empleo de las instituciones de democracia directa. En efecto, mientras en la década de 1980 se realizaron nueve consultas populares (18\%), durante la de 1990 el número saltó a 20 (41\%), en su mayoría para legitimar o rechazar reformas constitucionales. A partir de 2000 se han realizado 19 consultas (39\%): cuatro en Bolivia; cuatro en Uruguay; cuatro en Venezuela; tres en Ecuador; una en Brasil; una en Colombia; una en Costa Rica, y una en Panamá ${ }^{17 .}$

Importa apuntar, asimismo, que durante los últimos años, y sobre todo a partir del año 2000, se constata un uso cada vez mayor de los mecanismos de democracia directa en los países de la Región Andina. De los 19 procesos de democracia directa que han tenido lugar entre el año 2000 y marzo de 2010, 12 de ellos (o sea, un 63\%), tuvieron lugar en países andinos: cuatro en Bolivia; cuatro en Venezuela; tres en el Ecuador, y uno en Colombia.

16 Aquí se toman en cuenta las siete consultas realizadas a nivel nacional. Sin embargo, en Ecuador se han dado otras cinco consultas de carácter provincial, todas ellas en el año 2000, sobre la instauración de un régimen autonómico. En todas las consultas venció la opción de la autonomía con márgenes superiores a 80\% (Pachano, 2007: 8).

17 La otra consulta popular incluida en este análisis es el plebiscito de 1978 en Ecuador. 
Resumiendo, a escala nacional no es posible establecer una regla general que explique por qué algunos países han empleado más que otros estos mecanismos. Pareciera que la respuesta pasa por el contexto partidario y por la cultura política dominante de cada país. Así, por ejemplo, en Uruguay estos instrumentos preexistieron al proceso de restauración democrática. Después del retorno a la democracia sólo se registró como novedad el uso, hasta entonces desconocido, del recurso de derogación de leyes por medio de un referendo. Sin embargo, Uruguay sigue siendo uno de los países del mundo que tiene una larga y rica tradición en el uso de los institutos de democracia directa y que desde la primera mitad del siglo XX ha sabido combinar y articular adecuadamente los poderes representativos con la democracia directa (González Rissotto, 2007: 1).

Por el contrario, en Ecuador (el segundo país, como sabemos, que más veces ha utilizado estos mecanismos en la región latinoamericana), diversos presidentes en situación de asedio constante o de dudosa legitimidad, ante un sistema político partidario débil y fragmentado recurrieron frecuentemente a la opinión ciudadana para tratar de zanjar sus respectivas crisis políticas, con efectos no siempre positivos para el fortalecimiento de la gobernabilidad y la consolidación de la democracia en este país.

Por su parte, en los tres países más grandes de la región -Brasil, Argentina y México-, estos mecanismos han sido poco utilizados o no se han utilizado del todo. En Argentina, como vimos, a escala nacional registra únicamente una consulta popular a nivel nacional (sin efecto vinculante), sobre el tema del laudo limítrofe sobre el Canal de Beagle. En Brasil han tenido lugar dos experiencias: la primera fue la consulta obligatoria Ilevada a cabo en 1993 respecto a la posibilidad de implantar el parlamentarismo y la monarquía, que arrojó resultados adversos para ambas propuestas; la segunda experiencia, realizada en octubre de 2005, rechazó la iniciativa de prohibir el comercio de armas de fuego y municiones. Finalmente, en el caso de México, estos mecanismos no se utilizaron del todo a nivel nacional al no estar regulados en su ordenamiento constitucional.

\subsection{Origen de la utilización de las consultas populares en América Latina}

Como ya se indicó, 36 de las 49 consultas populares (o sea, el 73\% de las mismas), se originaron "desde arriba" y sólo 13 fueron iniciadas "desde abajo" (27\%), de las cuales 10 se llevaron a cabo en un solo país: Uruguay. Esta tendencia obedece al hecho de que si bien algunos Estados prevén la intervención de la ciudadanía para iniciar una consulta popular, en la mayoría de los países esta potestad se reserva al Ejecutivo o al Congreso.

Cabe destacar que varios presidentes latinoamericanos han utilizado estos mecanismos de democracia directa con distinta suerte durante el periodo en estudio. En Panamá, el ex Presidente Pérez Balladares fracasó en su intento de modificar la Constitución para autorizar la reelección. En Ecuador, el ex Presidente Sixto Durán logró respuestas favorables en una primera consulta-encuesta, pero negativas en la segunda, lo que debilitó su gestión de gobierno. La clase política uruguaya registró una derrota en 1994 al no haber logrado imponer una reforma constitucional que separaba las listas de votación municipal de las nacionales, reforma que 
había sido aprobada por dos tercios de los integrantes del Parlamento; luego, esa misma norma se incluyó en la reforma aprobada en 1996. El ex Presidente Fujimori, en Perú (1993), y el Presidente Chávez, en Venezuela (1999), utilizaron estos mecanismos de manera exitosa para consolidar sus respectivos proyectos políticos, si bien el primero debió renunciar a su tercer mandato presidencial como resultado del fraude cometido durante la elección de 2000 y la consiguiente crisis desatada. En 2007 el Presidente Chávez fracasó en su intento de ratificar las reformas constitucionales que aumentaban sus poderes presidenciales y reformaba la estructura del Estado venezolano en uno de carácter socialista. Sin embargo, más recientemente, en 2009, el Presidente Chávez logró que se aprobara la enmienda constitucional que le abre la reelección ilimitada y que también aplica para los demás cargos de elección popular.

En Colombia el Presidente Álvaro Uribe, amparado en una significativa aprobación popular a su gestión, intentó involucrar a la población en la toma de varias decisiones de distinta índole, presentando 18 preguntas que abarcaban temas diversos, desde la instauración del voto nominal y público en las corporaciones públicas de origen popular hasta la reducción del tamaño del Congreso y la aprobación de nuevos recursos para educación y saneamiento básico. Los resultados de este esfuerzo fueron negativos en razón de que sólo una de las preguntas logró la votación necesaria para su aprobación. En Bolivia, el referendo convocado por el ex Presidente Carlos Mesa involucró a la población en la toma de decisiones en materia de políticas públicas, relacionadas en esa oportunidad con la política energética. El resultado positivo del referendo permitió consolidar el estilo político de Mesa, basado en una relación directa con los ciudadanos. Por su parte, en Ecuador, el Presidente Correa dio un paso decisivo al contar con el apoyo ciudadano para aprobar la convocatoria a Asamblea Constituyente en la consulta de abril de 2007. Sin duda alguna, el apoyo a la propuesta del Presidente (que no tiene representación legislativa) es una victoria política que le abre un escenario propicio para desarrollar las reformas económicas y políticas que ha tratado de impulsar infructuosamente. Esta victoria fue seguida por la aprobación de la nueva Constitución Política en el referendo del 2008, consolidándose así el proyecto político del Presidente Correa. Por su parte, en Costa Rica, el Presidente Arias convocó a referendo en octubre de 2007 para aprobar el Tratado de Libre Comercio República Dominicana, Centroamérica y Estados Unidos. Esto se dio luego de un intenso debate a nivel nacional, y adelantándose a la opción de convocatoria por medio de la ciudadanía, situación que hubiera retrasado significativamente la fecha de la consulta y con ello, muy posiblemente, la imposibilidad de haber ratificado dicho Tratado a tiempo para su puesta en funcionamiento antes de marzo de 2008. Por último destaca el caso de Evo Morales, en Bolivia, que en 2008 promulga mediante ley la convocatoria a referendo revocatorio para su mandato, junto con el de vicepresidente y ocho prefectos departamentales. En este caso el Presidente Morales aseguró su continuidad, y más recientemente se adjudicó otra victoria cuando en enero del 2009 logró que se aprobara en consulta popular la nueva Constitución Política.

\subsection{El papel desempeñado por la sociedad civil}

Los ordenamientos constitucionales de varios de los países latinoamericanos prevén la iniciativa de la ciudadanía para reformar la Constitución, lo que en principio supone una 
mayor capacidad de decisión de parte de aquella. Sin embargo, debe advertirse que a la fecha únicamente Uruguay ha utilizado este mecanismo. La iniciativa de la sociedad civil, a través de movimientos ad hoc, se dio sólo en los casos de las reformas constitucionales planteadas en Uruguay en 1989, 1994 y 1999, para defender al sector de jubilados y pensionistas, a sectores ligados a la enseñanza y al Poder Judicial, habiendo triunfado únicamente las propuestas que presentaron los jubilados en 1989 y 1994.

También fueron de iniciativa popular los plebiscitos derogatorios planteados en Uruguay en 1989 y 2009, referidos a los abusos de los derechos humanos (Ley de Caducidad sobre el Tema de Derechos Humanos y Amnistía a los Militares) y promovidos por una coalición de partidos de izquierda y un movimiento ad hoc de la sociedad civil, que en ambas oportunidades fracasó. El de 1992, que rechazaba la posibilidad de privatizar parcialmente la empresa telefónica, fue promovido también por fuerzas partidarias de izquierda junto con el sindicato de trabajadores de la empresa y se aprobó; el de 2003, que rechazó la eventual asociación de la Administración Nacional de Combustibles, Alcohol y Portland (ANCAP) con otras empresas públicas o privadas, fue iniciado con una campaña de recolección de firmas en oposición a la propuesta. Como puede verse, en Uruguay la participación de las organizaciones de la sociedad civil ha sido limitada, dado que en los dos primeros casos se registró la alianza de esos movimientos sociales ad hoc con fuerzas partidarias. En Colombia, el "movimiento estudiantil de la $7^{\text {a }}$ papeleta" promovió los cambios que Ilevaron a la reforma constitucional de 1991. En Venezuela, diversas agrupaciones opositoras recogieron las firmas necesarias para convocar al referendo revocatorio del Presidente Chávez y, más recientemente en Bolivia, en el 2006, el Comité Pro Santa Cruz reunió unas 300.000 firmas válidas que dieron paso al primer referendo por iniciativa popular de la historia de este país. En el resto de los casos registrados en la región, la iniciativa correspondió principalmente al Presidente o al Parlamento, por lo general de acuerdo con las normas constitucionales que obligan a la consulta ciudadana.

En cuanto a la iniciativa popular legislativa en Argentina, por ejemplo, ha sido utilizada desde 2001, principalmente para propuestas de ley. Como producto de ello fue aprobada la ley "Contra el hambre más urgente". Otras iniciativas esperan su consideración en el Parlamento (Lissidini, 2007: 20).

Un caso que debe destacarse es la existencia de la iniciativa popular en Costa Rica a través de la Oficina de Iniciativa Popular de la Asamblea Legislativa. Ésta es una opción (no regulada constitucionalmente) que el Directorio de la Asamblea Legislativa creó en 1999 para que personas, sin ningún tipo de requisito, tengan la posibilidad de presentar anteproyectos de ley, sugerencias y aportes varios ante el Congreso. Estas iniciativas pueden ser acogidas de manera voluntaria por los diputados para presentarlas en la corriente legislativa ${ }^{18}$.

18 Desde abril de 1999 y hasta febrero de 2010, la Oficina de Iniciativa Popular de la Asamblea Legislativa de Costa Rica ha recibido 942 propuestas de legislación, de las cuales diez ya son Ley y otras cuarenta y cinco son proyectos que figuran dentro del orden del día de las Comisiones Legislativas (Asamblea Legislativa, marzo de 2010: http://www.asamblea.go.cr/Iniciativa_Popular/Lists/IniciativasRecibidas/AllItems.aspx). 
Otro caso similar es la Comisión de Legislación Participativa de Brasil, creada en mayo de 2001 como una Comisión dentro de la Cámara de los Diputados; por medio de ella, cualquier entidad civil organizada puede presentar propuestas de legislación. Las propuestas recibidas son analizadas por 18 diputados y, en el caso de aprobarse, se transforman en proyecto de ley y se inicia el proceso de tramitación legal en la Cámara (Fleischer y Bareto, 2008: 342).

En cuanto a los efectos que estos mecanismos han tenido, puede afirmarse que en general su uso en el ámbito nacional no ha dado mayor protagonismo a la sociedad civil, que ha desempeñado hasta la fecha, y sólo en unos pocos casos, más un papel de control y freno que de creación e innovación ${ }^{19}$.

Por su parte, el fortalecimiento de los niveles de control ciudadano sobre el gobierno o respecto de los otros órganos del sistema representativo sólo ha operado en forma limitada. En este sentido se pueden citar dos ejemplos. El primero, el referendo abrogatorio en Uruguay, cuyo resultado es todavía objeto de debate ${ }^{20}$. El segundo, el referendo de Venezuela en 2007 en el que se rechazaron las reformas constitucionales impulsadas por el Presidente Chávez que pretendían aumentar significativamente los poderes presidenciales y modificar la estructura del Estado democrático a uno de tipo socialista.

\subsection{Participación electoral}

En lo que refiere al nivel de participación electoral en las consultas populares, podemos observar que, en general, el porcentaje de votantes varía según el país y el tema en discusión. Sin embargo, no sólo existen diferencias importantes entre los países, sino dentro de un mismo país dependiendo del tema y del resultado.

Son especialmente notorios, por su reducida participación, los casos de Guatemala y Colombia, lo que coincide con el alto abstencionismo en elecciones presidenciales que caracteriza a estos países. Hay casos en que las consultas, traducidas a porcentaje sobre el padrón electoral, resultaron aprobadas o rechazadas por menos de 50\% de los ciudadanos inscritos. Sin embargo, en la mayoría de las situaciones en que ello ocurrió, los resultados no fueron impugnados, ni su legalidad o legitimidad cuestionadas por quienes resultaron derrotados.

19 Bernhard Thibaut señala que difícilmente se puede concluir que estos mecanismos refuercen a la "sociedad civil", pues no parecen disminuir el "desencanto" sino que, más bien, constituyen canales de articulación fuera de las elecciones normales (Thibaut, 1998: 65-88).

20 En el caso de la Ley de caducidad de la pretensión punitiva del Estado, que constituyó una suerte de amnistía general de posibles abusos cometidos por militares y policías durante el periodo dictatorial, se aceptó el resultado jurídico, pero continúa la disputa por la memoria y la historia, así como por reparaciones. En el caso de la Ley que permitía privatizaciones parciales en 1992 y que fue rechazada por la ciudadanía, el tema sigue en debate, especialmente en el área de la telefonía. Posteriormente formas de transmisión de datos y telefonía celular fueron otorgadas por concesión a operadores privados. 
El Cuadro 3 muestra el nivel de respaldo electoral obtenido desde 1978 a marzo de 2010 en los 12 países que pusieron en práctica consultas populares establecidas en las Constituciones Nacionales. Asimismo, se muestran los promedios por país y, de manera comparada, se promedia por décadas la participación electoral de estos mecanismos de democracia directa.

El promedio general de participación electoral para la región en materia de mecanismos de democracia directa ha sido de $67,58 \%$. Asimismo, se observa que en el comportamiento por país existen diferencias significativas. Al considerar el promedio de participación, observamos que Chile ${ }^{21}$ y Uruguay registran los promedios más altos (95,63\% el primero y $80,97 \%$ el segundo). Un segundo grupo de países se ubica en un nivel intermedio con promedios de participación de entre 50 y menos de 80\%: Argentina, Brasil, Bolivia, Costa Rica, Ecuador, Panamá, Perú y Venezuela. Por último, un tercer grupo se muestra con una afluencia electoral muy débil, registrando promedios inferiores a 50\%: Colombia $(32,36 \%)$ y Guatemala $(17,22 \%)$.

Otro aspecto a resaltar es la reducción en los promedios de participación electoral entre las décadas de 1980 y 1990, y el leve repunte con las realizadas después del año 2000, aunque siempre muy por debajo del promedio inicial registrado durante los 80 . En este sentido, durante los 80 las nueve consultas populares celebradas promediaron $82,92 \%$ de participación electoral, en las 20 consultas efectuadas durante los 90 el promedio bajó a $63,21 \%$, y en las 19 consultas realizadas después del 2000 el promedio subió levemente hasta $64,49 \%$.

En suma, destacan dos tendencias durante el periodo en estudio. La primera, que la región ha vivido un incremento importante en el uso de los mecanismos de democracia directa (sobre todo entre las décadas de 1980 y 1990) y, la segunda, refleja que el comportamiento electoral se movió de manera ambivalente, bajando radicalmente de los 80 a los 90, pero con una leve tendencia al alza en las consultas que se han realizado después del año 2000.

\subsection{Consecuencias sobre el sistema político}

\subsubsection{En general}

No hay elementos de juicio para afirmar que el uso de los mecanismos de participación ciudadana mejora o empeora el funcionamiento de un sistema político determinado. La mayoría de las democracias europeas recurren muy ocasionalmente a la consulta popular a escala nacional, y sobre todo en relación con temas de política exterior, mientras que Estados Unidos sólo la contempla en el ámbito estatal y local.

21 Cabe destacar que en Chile sólo pueden votar quienes se han registrado para tal efecto. Debido a que el registro electoral es voluntario, existe un número importante de chilenos que no se inscribe y, por lo tanto, no vota. Sin embargo, esta situación no se refleja en los datos de participación electoral. Vale la pena recordar, asimismo, que las tres consultas populares en Chile se dieron bajo el régimen autoritario de Pinochet. 


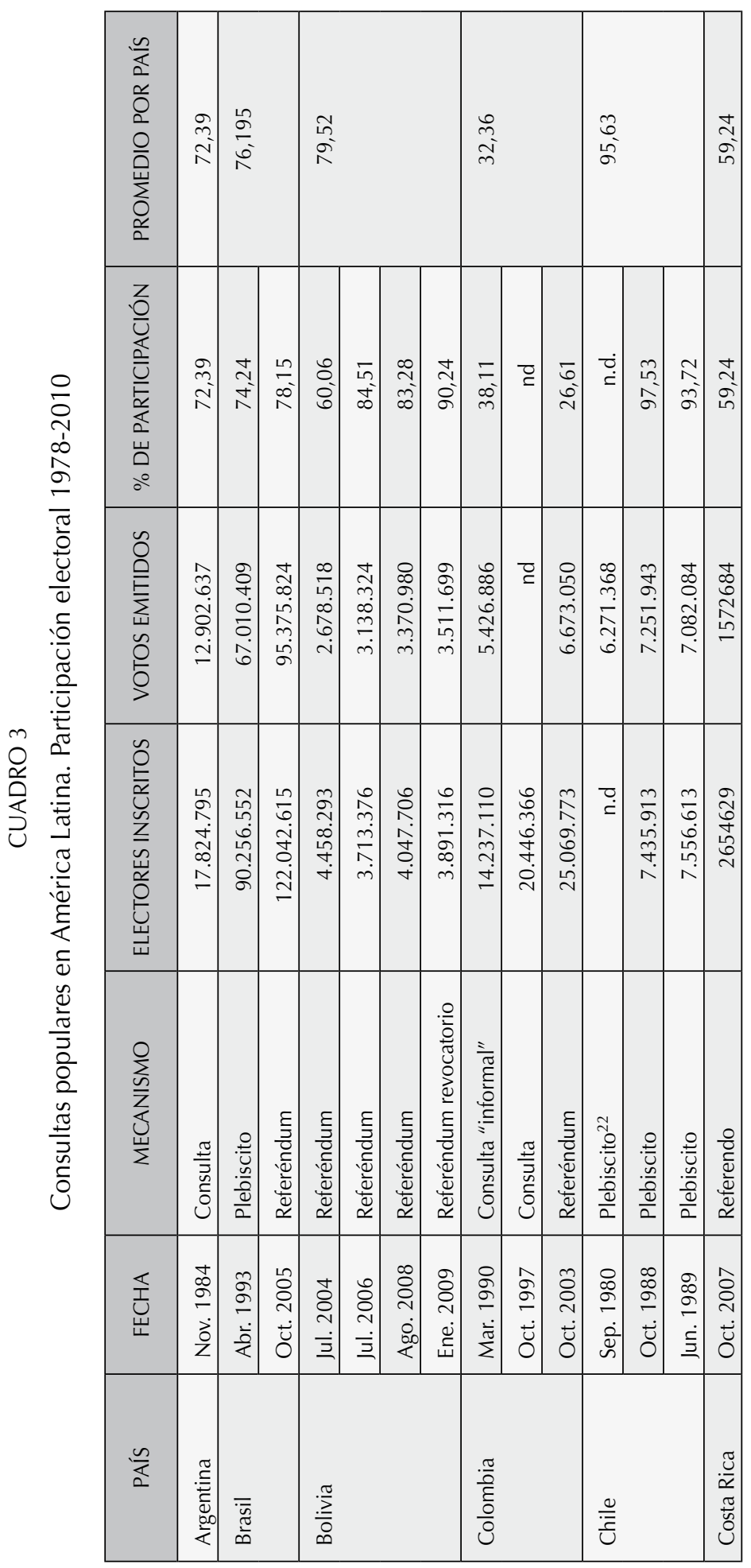

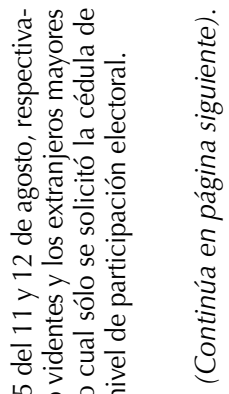

눙은은

ris

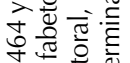

ن

느의 은 응

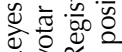

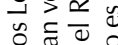

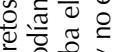

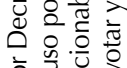

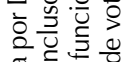

즌

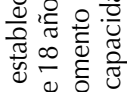

ن월 엉

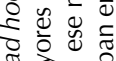

ป है

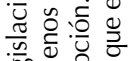

舟

능 으응

준 $\frac{\pi}{2} \frac{\pi}{2}$

के 원응

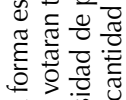

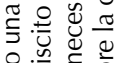

융흐응

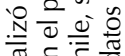

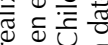

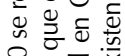

0
0
0
0

든 는 $\frac{\pi}{4}=$

记怘 志

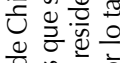

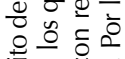

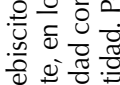

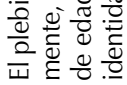




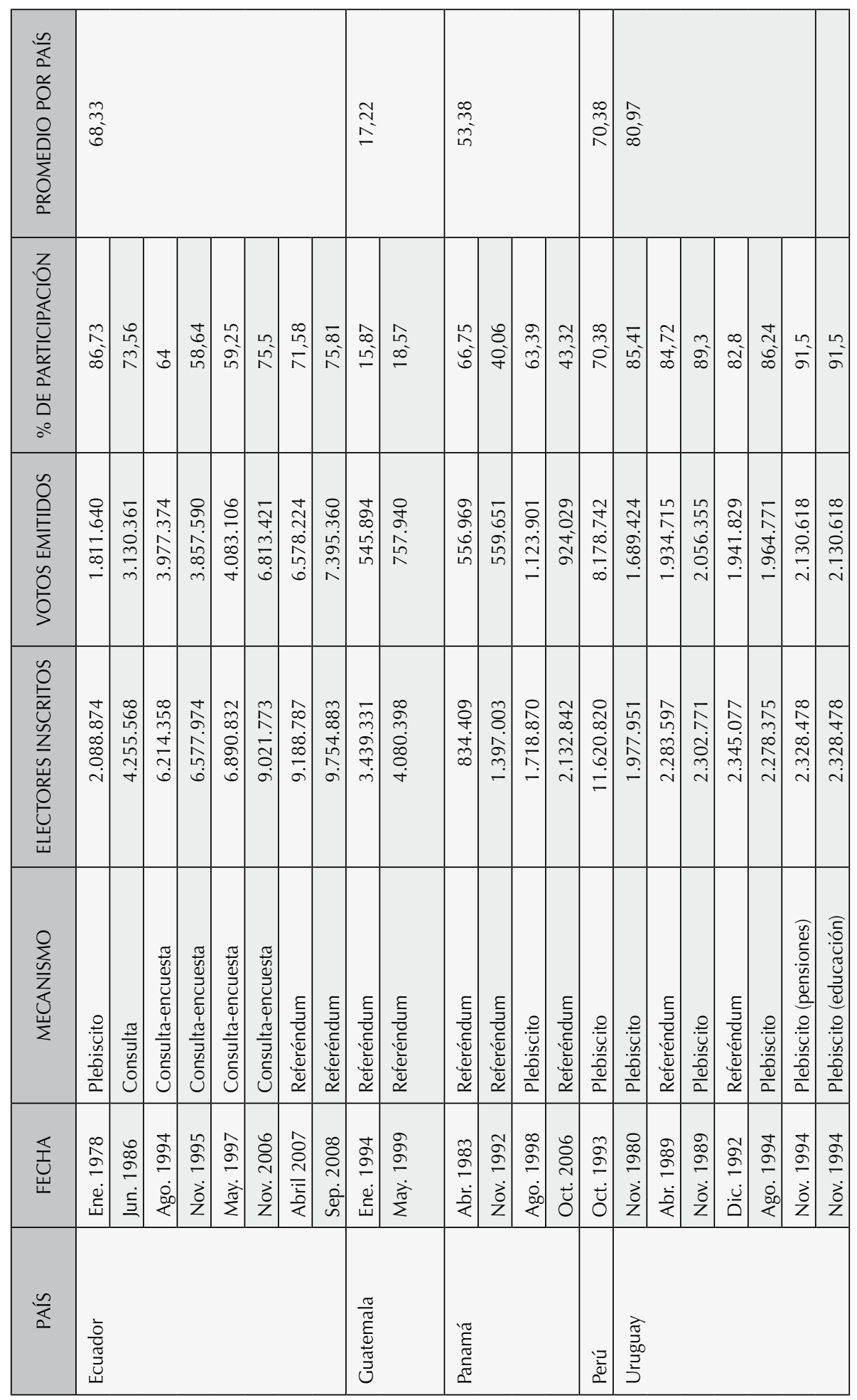




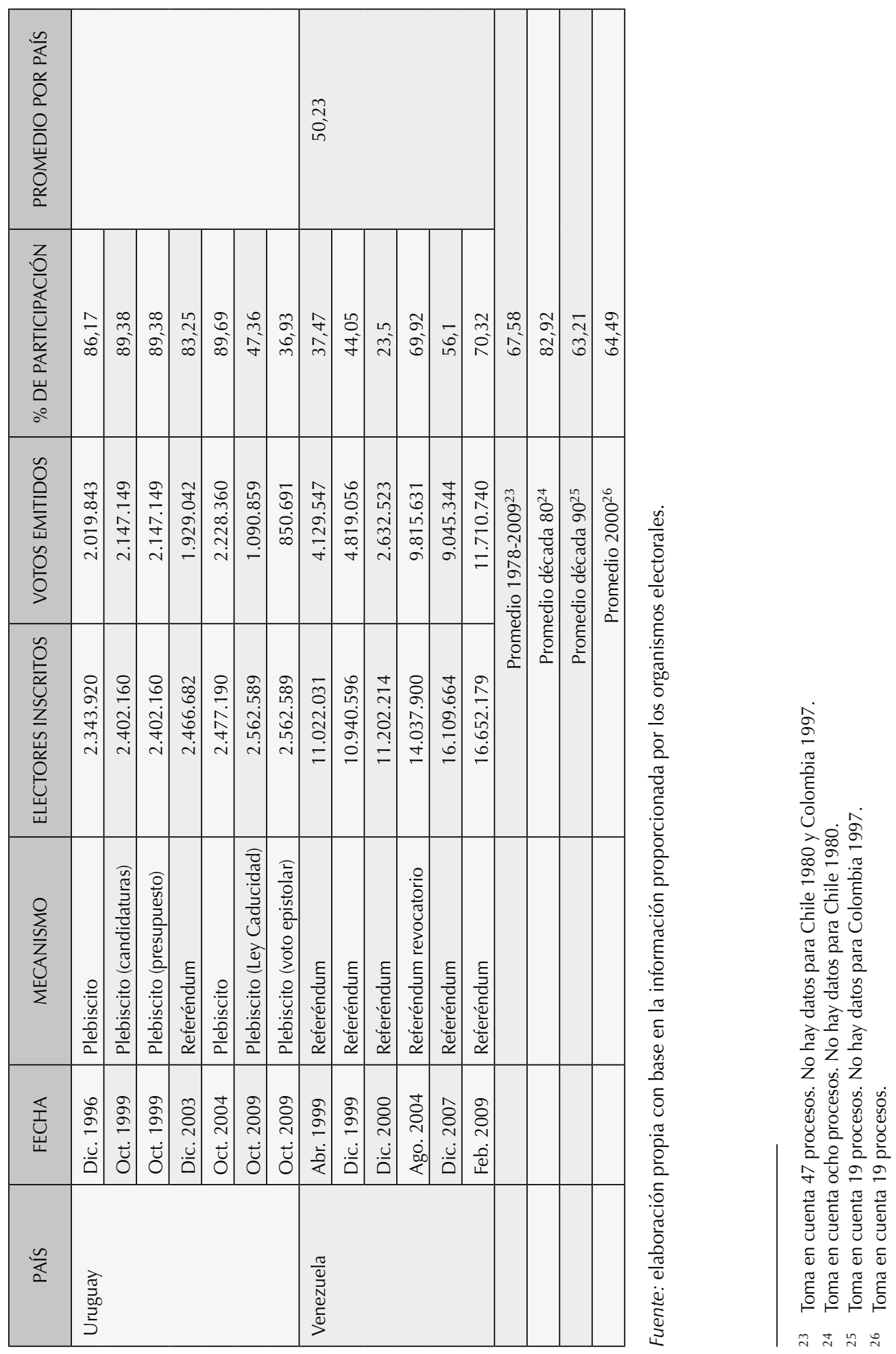


Hasta hoy en América Latina la experiencia tampoco parecería indicar que los mecanismos de democracia directa hayan tenido, en la mayoría de los casos, el impacto deseado en cuanto a mejorar la representación o la participación, ni que hayan coadyuvado a disminuir el descontento con la política y los partidos, actuando más bien como canales de expresión de este "desencanto" fuera de las elecciones regulares.

\subsubsection{En materia de estabilidad política}

No puede afirmarse tampoco que los mecanismos de democracia directa, tal como se han utilizado hasta ahora, hayan mejorado o complicado de manera sustancial la estabilidad política. Como todo instrumento de ingeniería electoral, éstos deben formar parte de una arquitectura mayor y, en ese marco, debe analizarse su funcionamiento. En general, estos mecanismos no se han utilizado para resolver controversias entre el Parlamento y el Ejecutivo, salvo de manera indirecta en Ecuador, donde el ex Presidente Sixto Durán recurrió a ellos sin éxito para tratar de mejorar los niveles de legitimidad de su debilitada gestión. En el caso de Venezuela, donde sectores de oposición procuraron la revocatoria del mandato del Presidente Hugo Chávez por medio de un referendo, los resultados mostraron la existencia de una ciudadanía polarizada y no abonaron nada a la estabilidad política del país. Más recientemente, en 2006, el referendo sobre las autonomías departamentales en Bolivia mostró las diferencias políticas internas entre la derecha y la izquierda, por un lado, y entre occidente y oriente, por otro.

En algunos países, y en determinados momentos, el uso de estos mecanismos puede incluso considerarse negativo para la estabilidad política. Ecuador es de nuevo un buen ejemplo de ello. Las sucesivas consultas no vinculantes sin instrumentación posterior llevaron a acentuar la ingobernabilidad del país. Si bien no puede atribuírseles responsabilidad directa en la pérdida de estabilidad política que llevó a la caída de tres presidentes constitucionales, tampoco puede decirse que hayan contribuido positivamente en favor de la estabilidad.

\subsubsection{En materia de reforma política}

En cuanto a la reforma política, los mecanismos de democracia directa parecerían carecer de una tendencia clara, aunque en los últimos años han sido centrales para aprobar reformas significativas como se explica más adelante. En algunos casos favorecieron soluciones conservadoras como fue en 1993 el rechazo al cambio de régimen de gobierno y sistema político en Brasil. En otros casos han sido más bien revolucionarios y han tenido como objetivo desestructurar el régimen establecido, como el Movimiento de la $7^{\text {a }}$ Papeleta en Colombia y la iniciativa de revocatoria de mandato en Venezuela.

En otros casos los resultados se muestran contradictorios. La separación de elecciones municipales de las nacionales, rechazada por la ciudadanía uruguaya en 1994, se aprobó en 1996. Asimismo, en julio de 1986, la ciudadanía ecuatoriana rechazó la posibilidad de aceptar candidaturas independientes de los partidos, pero luego las aceptó en 1994. Finalmente, en diciembre de 2007, las reformas constitucionales impulsadas por el Presidente 
Chávez que buscaban establecer un Estado Socialista y la reelección presidencial indefinida fueron rechazadas por la ciudadanía. Sin embargo, en febrero de 2009 se ratificaron en referéndum las reformas constitucionales que permiten la reelección indefinida para todos los puestos de elección popular, revirtiendo en parte el rechazo efectuado en 2007 con respecto a este tema.

Sin embargo, Ilama la atención el uso de consultas para la aprobación popular y puesta en vigencia de nuevas Constituciones Políticas; la de Ecuador en 2008 y Bolivia en 2009. Estos son dos ejemplos importantes de cómo el uso de estos mecanismos puede generar cambios políticos significativos.

\subsubsection{En relación con las reformas económicas}

La complejidad de los temas económico-financieros determina un alto grado de dificultad para intentar resolverlos mediante la participación ciudadana a través del uso de mecanismos de democracia directa. Por ello, las legislaciones de la mayoría de los países han excluido expresamente estas materias como objeto de eventuales consultas populares. Empero, en algunos países, entre ellos Uruguay, a iniciativa de la sociedad civil y por lo general con la adhesión de partidos políticos de centro-izquierda, se intentó usar estos mecanismos para imponer límites a las reformas económicas. El caso paradigmático es la derogación de la ley que permitía la privatización parcial de la empresa telefónica uruguaya en 1992. Sin embargo, el mismo esquema no siguió adelante en los años posteriores, cuando se intentó someter a referendo una ley marco sobre la distribución de electricidad y gas. Tampoco prosperó un intento de comenzar a cuestionar el sistema privado de retiros y pensiones, aunque en este caso se debió a razones formales, ya que la Corte Electoral entendió que no procedía la interposición del recurso por ser la materia jubilatoria de iniciativa privativa del Poder Ejecutivo. Asimismo, en 2003 se acogió mediante referendo un recurso contra la ley que permitía que la ANCAP pudiera asociarse con empresas públicas y privadas, nacionales o extranjeras, para la refinación y distribución de combustibles derivados del petróleo.

En Ecuador el intento de grupos de la sociedad civil de convocar a una consulta popular contra el plan económico del gobierno del Presidente Gustavo Noboa y la dolarización, fracasó al no haberse reunido el número suficiente de firmas, según informó la autoridad electoral.

En Colombia, en 2003, el Presidente Uribe trató de lograr la aprobación de la ciudadanía en temas diversos, como la obtención de nuevos recursos para educación y saneamiento básico, el saneamiento de las finanzas públicas, la eliminación de pensiones y salarios mayores a 25 salarios mínimos mensuales que se pagan con cargo al Estado, entre otros. La respuesta de la ciudadanía impidió que se aprobaran las reformas propuestas, al no alcanzar el umbral necesario para su convalidación. En Bolivia, por el contrario, la ciudadanía dio luz verde, en julio de 2004, a la propuesta del Presidente Carlos Mesa para la abrogación de la Ley de Hidrocarburos de 1989, promulgada por Gonzalo Sánchez de Lozada, y a la recuperación de la propiedad estatal de todos los hidrocarburos. 
Finalmente en Costa Rica, en 2007, y de manera poco usual en la región, se ratificó en referendo el Tratado de Libre Comercio República Dominicana, Centroamérica y Estados Unidos. En este sentido, cabe advertir que por su naturaleza en América Latina la ratificación de tratados comerciales es tradicionalmente de competencia del Poder Legislativo, razón por la cual la experiencia de Costa Rica abre una nueva opción de participación ciudadana sobre nuevos temas económicos.

\subsection{Consideraciones finales}

Un balance preliminar de todo lo hasta aquí analizado arroja diez consideraciones finales principales:

1. La diversidad terminológica existente sobre los diferentes mecanismos de democracia directa en los textos constitucionales de los países latinoamericanos genera confusión. Es necesario, por lo tanto, avanzar en dirección de una mayor precisión sobre esta cuestión, para de este modo poder entender mejor de qué estamos hablando cuando analizamos los diversos mecanismos de democracia directa.

2. Pese a la generalizada incorporación de los mecanismos de democracia directa en los textos constitucionales, la mayoría de los sistemas políticos latinoamericanos mantiene, en la práctica, un bajo componente de democracia directa en el nivel nacional, con excepción de Uruguay y en menor medida Ecuador, Venezuela, Bolivia y Panamá en ese orden. Hay una riqueza mucho mayor, con una variedad de mecanismos y modalidades, en el ámbito estatal y local/municipal latinoamericano, cuyo estudio comparado sigue inexplorado y abierto a una necesaria investigación.

3. A pesar de la diversidad de mecanismos de democracia directa, hasta la fecha las consultas populares (referendos o plebiscitos) son las de mayor uso en la región. La experiencia también permite comprobar que la aplicación de las consultas populares se ha gestado primordialmente "desde arriba", pues en 36 de las 49 consultas realizadas los poderes Ejecutivo o Legislativo han ocupado un papel predominante, a pesar de que en nueve de los 16 países con regulación sobre estos mecanismos los ciudadanos tienen la posibilidad de convocar a consulta popular, bajo diversas modalidades y con respecto a diferentes temas.

4. El análisis comparado latinoamericano de la aplicación práctica de estos mecanismos evidencia que su uso está muy condicionado por las fuerzas y las debilidades del sistema político dentro del que operan (régimen político, sistema de partidos, comportamiento electoral, cultura política). En otras palabras, los mecanismos de democracia directa no constituyen un subsistema blindado a estas características, sino que, por el contrario, se ven altamente influenciados por éstas.

5. En cuanto a los resultados en la aplicación de estos mecanismos, cabe destacar que en nuestra región han tenido un resultado mixto, oscilante entre intentos de manipulación neopopulistas, por una parte, y posiciones conservadoras o tradicionalistas, por otra. En 
dos casos extremos en los que regímenes autoritarios recurrieron a esos instrumentos para mantenerse en el poder, la estrategia produjo el efecto opuesto (Uruguay en 1980 y Chile en 1988).

6. Por otro lado, es importante considerar varios aspectos adicionales a la hora de evaluar el impacto de los mecanismos de la democracia directa. En primer lugar, que la adopción y aplicación de estos mecanismos es bastante reciente (salvo en el caso de Uruguay que data de 1934), y que por lo tanto estamos ante un fenómeno bastante nuevo de las democracias de la región, por lo que sería recomendable dejar transcurrir un poco más de tiempo antes de intentar extraer conclusiones definitivas sobre su rango de aplicación y sus efectos. Y, en segundo lugar, hay que poner atención al uso creciente que se le está dando a estos mecanismos en varios países de la región andina, sobre todo en los últimos años, en contextos de alta polarización política, elevada fragmentación partidista y asociados a procesos de reformas constitucionales "refundacionales" (Bolivia, Ecuador y Venezuela).

7. Con respecto a la participación electoral se advierte que el promedio general para la región (entre 1978 y marzo de 2010) es de 67,58\%. Asimismo, los promedios regionales por año muestran que la participación electoral se ha venido reduciendo, sobre todo al comparar la década de los 80 con la de los 90 . Asimismo, el comportamiento por país (e incluso dentro de un mismo país), registra diferencias importantes. Se destacan particularmente los altos niveles de participación electoral en países como Uruguay y Chile (si bien este es un caso ad hoc) y los preocupantes niveles de abstención que han presentado en el uso de estos mecanismos países como Colombia y Guatemala.

8. En sociedades como las latinoamericanas, donde persisten elevados niveles de pobreza (por encima del 34\% de acuerdo con la CEPAL para el año 2009) y desigualdad, el uso de los mecanismos de democracia directa puede, en algunos casos, ayudar a revertir la tendencia a la deslegitimación del sistema político, porque constituyen un medio adicional de expresión política que permite a la población manifestar su frustración con las autoridades. Sin embargo, en este tipo de contextos resulta también esencial considerar el riesgo de su utilización patológica o desvirtuada con fines demagógicos y antidemocráticos.

En efecto, los mecanismos de democracia directa deben ser vistos como instrumentos para consolidar el sistema democrático, que complementan, pero no sustituyen, a las instituciones de la democracia representativa. Si bien es cierto que los primeros pueden fortalecer la legitimidad política y abrir canales de participación que faciliten una reconciliación entre los ciudadanos y sus representantes, los partidos políticos y el Poder Legislativo deben mantenerse como las instituciones centrales donde se articulan y combinan las preferencias ciudadanas, $y$ deben fortalecerse en aras de mejorar la calidad y legitimidad de la representación democrática.

Aunque en un principio algunos pensaron que la democracia participativa iba en contravía de la democracia representativa, ahora se acepta, en general, que son fórmulas 
complementarias (De la Calle, 2007: 9). En ocasiones, sin embargo, se asigna a los mecanismos de democracia directa funciones y expectativas sobredimensionadas, por encima de sus capacidades. Pero incluso más allá de la valoración que pueda hacerse en relación con su empleo, hay que aceptar que estos mecanismos han Ilegado para quedarse y que en algunos países (como en la actualidad ocurre en la Región Andina) tendrán una relevancia creciente. De ahí que el tema central pase por cómo utilizarlos adecuadamente y, más aún, cuándo y en qué casos.

9. De ahí la importancia de definir un marco legal adecuado a fin de mejorar su funcionamiento, pues en algunos países aún existen vacíos significativos en la reglamentación de estos institutos para su aplicación en la práctica. Resulta además fundamental que la normativa especifique claramente los temas que se pueden abordar mediante los distintos mecanismos de democracia directa. De esta forma, la democracia se verá fortalecida en la medida en que se consolide el uso de estos mecanismos y contribuya, a la vez, a fortalecer a la ciudadanía. Así, el esfuerzo realizado por ampliar los espacios de democracia directa debe ir acompañado por programas de fortalecimiento de educación cívica, para lo cual es necesario desarrollar valores asociados con el ejercicio de una participación política que trascienda la mera participación electoral.

10. El empleo adecuado de estos mecanismos exige, como premisa lógica, la existencia de un Estado democrático dotado de unos derechos fundamentales plenamente garantizados y en donde el pluralismo político goce de total efectividad. Demanda, además, la plena vigencia de la libertad de expresión e información y la no manipulación de la opinión pública, así como condiciones de equidad del proceso. No hay que olvidar que en más de una ocasión han sido los enemigos de la libertad y de la democracia los que han recurrido a su uso (Aragón y López, 2000: 981).

Por ello, somos de la opinión, como lo demuestra la práctica latinoamericana, de que los mecanismos de democracia directa significan un elemento distorsionador en ausencia de instituciones democráticas representativas eficientes, fundadas en un sistema de partidos políticos estable y correctamente arraigado en la sociedad. Es necesario, por lo tanto, Ilevar a cabo un proceso de reforma en materia de democracia directa dirigido a democratizar el empleo de estos institutos, es decir, hacerlos más accesibles a la ciudadanía.

Resumiendo, en sociedades como las nuestras, con altos niveles de pobreza, con la peor desigualdad del mundo, con instituciones débiles y, sobre todo, donde la política vive "bajo sospecha", si los mecanismos de democracia directa son debidamente utilizados pueden ayudar a contrarrestar la tendencia a la deslegitimación del sistema político. De lo contrario, lejos de constituir un instrumento para la participación directa del pueblo en la adopción de decisiones concretas, pueden convertirse en un medio de manifestación del descontento social al margen de los procesos electorales, con consecuencias negativas para la gobernabilidad democrática. 
En efecto, sin instituciones políticas fuertes y arraigadas, el uso de estas instituciones puede maximizar el conflicto y, como bien señala Sartori, Ilegar a representar la encarnación de la "tiranía de las mayorías" (Sartori, 1989: 156ss). Por lo tanto, y de cara al actual contexto económico, social y político regional, resulta esencial evitar el peligro de un uso patológico de estos mecanismos. En mi opinión, es aconsejable una utilización prudente y no desvirtuada de los mecanismos de democracia directa, especialmente en lo que se refiere a su uso en el ámbito nacional. Por todo ello, y más allá del valor agregado que pueda derivarse de su aplicación, sobre todo a escala local (espacio que consideramos idóneo para su ejercicio), la coyuntura latinoamericana demanda prestar atención urgente y prioritaria al fortalecimiento del Estado democrático y al mejoramiento de la eficacia de los mecanismos y órganos centrales de la democracia representativa, en particular a la institucionalización y el fortalecimiento de un sistema de partidos políticos estable, eficaz y democrático.

\section{BIBLIOGRAFÍA}

Altman, David (2007): Democracia directa en América Latina: evidencias, deficiencias y suficiencias, ponencia presentada en la Conferencia Internacional: Democracia Directa en América Latina, 14 y 15 de marzo, Buenos Aires.

Aragón, M. y J. López (2000): "Plebiscito", en Diccionario electoral (t. II), Instituto Interamericano de Derechos Humanos, San José.

Asamblea Legislativa de la República de Costa Rica (2009): Oficina de Iniciativa Popular, en: http:// www.asamblea.go.cr/inciatva/inicialg_recib.htm

Barreto, Leonardo y David Fleischer (2008): "Reformas políticas y democracia en Brasil”, en D. Zovatto y J. Orozco (coord.): Reforma Política y Electoral en América Latina 1978-2007, IIJ/UNAM, IDEA Internacional, México.

Corporación Latinobarómetro (2009): Informe del Latinobarómetro 2009, en: http://www. latinobarometro.org

De la Calle, Humberto (2007): Instrumentos de la democracia directa: el caso de Colombia, ponencia presentada en la Conferencia Internacional: Democracia Directa en América Latina, 14 y 15 de marzo, Buenos Aires.

EMOL (2004): http://www.emol.com/noticias/internacional/detalle/detallenoticias.asp? idnoticia $=147914$

González, Rodolfo, Antonio Lizarazo, Iván Marulanda y Daniel Zovatto (2004): “Democracia Directa y referéndum en América Latina", Cuaderno de Diálogo y Deliberación, Corte Nacional Electoral de Bolivia, en: http://www.cne.org.bo/centro_doc/cuadernos_dia/cuaderno_dia1_ democracia.pdf

González Rissotto, Rodolfo (2007): Democracia directa: el caso de Uruguay, ponencia presentada en la Conferencia Internacional: Democracia Directa en América Latina, 14 y 15 de marzo, Buenos Aires.

Kornblith, Miriam (2007): Democracia directa y revocatoria de mandato en Venezuela, ponencia presentada en la Conferencia Internacional: Democracia Directa en América Latina, 14 y 15 de marzo, Buenos Aires. 
Lissidini, Alicia (2007): Democracia directa Latinoamericana: entre la participación y la delegación, ponencia presentada en la Conferencia Internacional: Democracia Directa en América Latina, 14 y 15 de marzo, Buenos Aires.

Lissidini, Alicia, Yanina Welp y Daniel Zovatto (coords.) (2008): Democracia Directa en Latinoamérica, IDEA/USAM/C2D, Prometeo Libros, Argentina.

Pachano, Simón (2007): Democracia directa en Ecuador, ponencia presentada en la Conferencia Internacional: Democracia Directa en América Latina, 14 y 15 de marzo, Buenos Aires.

Payne, Mark, Daniel Zovatto y Mercedes Mateo (coords.) (2006): La política importa: democracia y desarrollo en América Latina, Banco Interamericano de Desarrollo (BID)-Instituto para la Democracia y la Asistencia Electoral (IDEA).

Romero Ballivián, Salvador (2007): La democracia directa en Bolivia, ponencia presentada en la Conferencia Internacional: Democracia Directa en América Latina, 14 y 15 de marzo, Buenos Aires.

Sartori, G. (1989): Teoría de la democracia. El debate contemporáneo, Alianza Universidad, México.

Thibaut, B. (1998): "Instituciones de democracia directa", en D. Nohlen, S. Picado y D. Zovatto (comps.): Tratado de derecho electoral comparado de América Latina, Instituto Interamericano de Derechos Humanos, Universidad de Heidelberg, International IDEA, Tribunal Electoral del Poder Judicial de la Federación, Instituto Federal Electoral, Fondo de Cultura Económica, México.

Zovatto, Daniel (2007): "América Latina después del rally electoral 2005-2006: algunas tendencias y datos sobresalientes", Revista Nueva Sociedad, № 207, enero-febrero.

(2007): "Las instituciones de democracia directa", en D. Nohlen, D. Zovatto, J. Orozco y J. Thompson (comps.): Tratado de derecho electoral comparado de América Latina, Instituto Interamericano de Derechos Humanos, Universidad de Heidelberg, International IDEA, Tribunal Electoral del Poder Judicial de la Federación, Instituto Federal Electoral, Fondo de Cultura Económica, México.

(2008): "Las instituciones de la democracia directa a nivel nacional en América Latina. Balance comparado: 1978-2007", en A. Lissidini, Y. Welp y D. Zovatto (coords.): Democracia Directa en Latinoamérica, IDEA/USAM/C2D, Prometeo Libros, Argentina.

Zovatto, Daniel y José de J. Orozco (coords.) (2008): Reforma Política y Electoral en América Latina 1978-2007, IIJ/UNAM, IDEA Internacional, México. 